\title{
La estética de la escucha: diálogos sensoriales, lúdicos y poéticos con la ciudad
}

\section{The Aesthetics of Listening: Sensory, Playful and Poetic Dialogues with the City}

Artículo recibido el 9 de septiembre de 2020; devuelto para revisión el 22 de febrero de 2021; aceptado el 6 de abril de 202I; https://doi.org/IO.2220I/iie.I8703062e.202I.II9.2753.

Laura Apolonio Universidad de Granada, Facultad de Bellas Artes, Departamento de Pintura, lauraapo@ugr.es, https://orcid.org/oooo-0002-4839-66IX/

Líneas de investigación Arte; cuerpo; espacio; caminar; arte público.

Research lines Art; body; space; walking; public art.

Publicación más relevante "El cuerpo es el corazón del mundo. Entrevista a David Le Breton", Arte, Individuo y Sociedad 32, núm. 3 (2020): 829-834.

Mar Garrido-Román Universidad de Granada, Facultad de Bellas Artes, Departamento de Dibujo, margr@ugr.es, https://orcid.org/oooo-ooo2-I454-247I

Líneas de investigación Videocreación; arte sonoro; fotografía; imagen en movimiento.

Research lines Videocreation; sound art; photography; moving image.

Publicación más relevante "Copias de copias: la apropiación de la apropiación en arte contemporáneo”, Observar II, núm. 2 (2017): 203-217.

Resumen El objetivo de este artículo es revindicar el potencial creativo de la escucha como experiencia estética y herramienta artística. Al partir de consideraciones sobre el urbanismo sensorial, la semiótica y la poética de la ciudad, iremos profundizando nuestra investigación en la fenomenología de la escucha, analizaremos el soundwalking (paseo sonoro) desde sus orígenes hasta algunos de los ejemplos más sugerentes de artistas contemporáneos, mostraremos cómo la escucha, unida al paseo, constituye una potente herramienta capaz de ampliar y transformar nuestra percepción del mundo. Por último, presentaremos nuestro proyecto de Cartografias sonoras de Granada, una creación de paseos sonoros por la ciudad para invitar a los caminantes a descubrir una nueva dimensión estética que abre la conciencia a un mundo sugerente, frágil y efímero, 
siempre presente, aunque a menudo invisibilizado por la vida apresurada en su afán productivo.

Palabras clave Urbanismo sensorial; caminar; soundwalking; arte sonoro; paisaje sonoro.

\begin{abstract}
The aim of this article is to claim the creative potential of listening to sounds in urban planning and architecture as well as in other artistic fields. Starting from considerations on sensory urbanism, semiotics and poetics of the city, it sets out to deepen research into the phenomenology of listening by analyzing soundwalking from its origins to some of the most suggestive examples of contemporary artists, showing how listening to sounds, together with walking, is a powerful tool for expanding and transforming our perception of the world. Finally, it presents the project of Sound Cartographies of Granada, a creation of soundwalks around the city to invite walkers to discover a new aesthetic dimension that opens consciousness to a suggestive, fragile and ephemeral world, always present, although often made invisible in the daily rush of a life obsessed by productivity.
\end{abstract}

Keywords Sensory urbanism; walking; soundwalking; sound art; soundscape. 
DOI: https://doi.org/10.22201/iie.18703062e.2021.119.2753

\author{
LAURA APOLONIO Y MAR GARRIDO-ROMÁN \\ UNIVERSIDAD DE GRANADA
}

\title{
La estética de la escucha: \\ diálogos sensoriales, lúdicos y poéticos con la ciudad
}

\section{El urbanismo sensual. Sensorialidad frente a racionalidad}

$\mathrm{E}$

n su texto Sull'immagine sonora della $\operatorname{città~}^{\mathrm{I}}$ (Sobre la imagen sonora de la ciudad), ${ }^{2}$ Antonella Radicchi cuenta que cuando le preguntaron a la primera mujer cosmonauta, Valentina Tereshkova, sus impresiones sobre su experiencia en el espacio, ella respondió que lo que más le llamó la atención, más aún que la asombrosa vista del universo, fue la terrible ausencia de los sonidos naturales, sobre todo el de la lluvia. Experiencia que, escribe Radicchi, ${ }^{3}$ recuerda al protagonista de la película Solaris de Tarkovski que, en su nave espacial, necesita reconstruir el ruido del viento con un papel de seda y un ventilador. Estos ejemplos son significativos sobre la importancia de los sonidos y de los valores que les atribuimos. El ambiente sonoro que nos envuelve fundamenta en gran medida, tanto la construcción de nuestra identidad como la transmisión de nuestra memoria, ya que no sólo es importante el ecosistema sonoro que habitamos, sino también todos los sonidos que han ido tejiendo nuestro sustrato mnemónico.

Antonella Radicchi propone crear un nuevo tipo de urbanismo sensorial capaz de proyectar espacios urbanos que potencien la escucha sonora al despertar a sus transeúntes a la conciencia corporal, rompiendo con una movilidad

I. Antonella Radicchi, Sull'immagine sonora della città (Florencia: Firenze University Press, 20I2).

2 Todas las traducciones de textos originales en el artículo son de las autoras.

3. Radicchi, Sull'immagine sonora della città, VII. 


\section{DOI: https://doi.org/10.22201/iie.18703062e.2021.119.2753}

I4

LAURA APOLONIO Y MAR GARRIDO-ROMÁN

urbana estrictamente funcional en la que los ciudadanos se mueven como autómatas sin ser conscientes ni del espacio que atraviesan ni de su propio cuerpo en movimiento. Se pretende así activar la percepción de lo cotidiano para descubrir su infinita riqueza y afianzar los vínculos entre los ciudadanos y su propia ciudad, intensificando el sentimiento de presencia y pertenencia a un lugar. Lo interesante de su propuesta es que considera el ambiente sonoro en el urbanismo desde un enfoque creativo y constructivo y no sólo negativo, de protección de la contaminación acústica, como es tratado normalmente. Radicchi muestra la influencia del paisaje sonoro en las relaciones semánticas de la ciudad y en la construcción de significados. Potenciar el espacio sonoro, cuya característica es siempre fluida y envolvente, entra en conflicto directo con un tipo de urbanismo racionalista, rígido y funcionalista que obedece a ideologías de control y dominio del ciudadano, en lugar de fomentar la plena realización de sus cualidades más humanas.

\section{La ciudad como poema}

Roland Barthes, en la interesantísima publicación póstuma titulada La aventura semiológica, que recopila los textos de sus clases y conferencias, afirma, en el capítulo "Semiología y urbanismo", el carácter siempre significante del espacio habitado humano (cualquier tipo de espacio, no sólo el urbano) porque el ser humano habita su entorno transformándolo y esta transformación es siempre causa y consecuencia de una actividad significante. "La ciudad [escribe] es un discurso y este discurso es verdaderamente un lenguaje: la ciudad habla a sus habitantes, nosotros hablamos a nuestra ciudad, la ciudad en la que nos encontramos, sólo con habitarla, recorrerla, mirarla». ${ }^{4}$ Toda ciudad es una escritura, porque todos sus elementos significan y todos los movimientos de sus habitantes responden a intenciones significativas. Existe un verdadero diálogo semántico entre la ciudad y sus habitantes.

Barthes se sorprende de que, siendo la organización del espacio esencialmente semántica, este aspecto haya sido tan poco considerado por los urbanistas. El único que ha enfocado sus investigaciones en términos semánticos es, según Roland Barthes, Kevin Lynch quien ha intentado definir la imagen de la ciudad,

4. Roland Barthes, La aventura semiológica, trad. Ramón Alcalde (Barcelona: Ediciones Paidós, 1993 [1985]), 260. 
es decir, comprender cómo sus habitantes la perciben. En su libro, La imagen de la ciudad, 5 Lynch ofrece una lectura estructural de la ciudad dividiéndola en las categorías semánticas básicas a partir de las cuales todo habitante "escribe" o representa su ciudad. Estas unidades son: las sendas (los trayectos o caminos que sigue el ciudadano normalmente), los bordes (los límites entre dos zonas bien definidas), los hitos (los puntos de referencia como pueden ser un monumento, un edificio emblemático, entre otros), los nodos (los puntos de convergencia como plazas, glorietas, cruces, entre otros) y los barrios (las distintas zonas de la ciudad). Según Lynch, se puede definir el grado de representación o imageability de una ciudad, es decir, la facilidad con la que una ciudad puede dar lugar a imágenes. Cuanto más fácilmente la ciudad penetre en el imaginario de sus habitantes más semántica será la relación entre ambos. Cuanto más alto sea el intercambio de significantes/significados, más proficua la escritura/lectura de la ciudad por sus habitantes y más enriquecedora su relación de habitabilidad. Barthes subraya también la "función imaginaria del paseo, que [escribe] en toda ciudad es vivido como un río". ${ }^{6}$ Las ciudades sin paseo marítimo, río, lago o curso de agua, presentan una mayor dificultad de adaptación de sus habitantes. La presencia del elemento acuático hace vibrar el imaginario además de invitar al paseo y favorecer así la relación poética con la ciudad.

El urbanismo sensorial rescata la creatividad humana y su capacidad inherente de generar significado, cualidad censurada y anestesiada en la ciudad funcionalista en la que los ciudadanos sólo se mueven siguiendo un orden que responde al dictamen de la eficiencia productiva. La creación de sentido es lo que tiene para Barthes el máximo valor. Para él la investigación semiológica responde a esta "pasión del sentido", comprender el misterio de la construcción del sentido, más allá del lenguaje, no dar nada por supuesto, no perder nunca "le frisson du sens" (el estremecimiento del sentido). 7 Para él todo objeto tiene significado porque todo objeto es social. Al partir del concepto de "bricolaje" de Claude Levi-Strauss, muestra cómo la invención y construcción de un objeto es siempre una creación de sentido. De la misma manera, la ciudad es un escenario lleno de significados y al pasear en ella nos convertimos en lectores-poetas. Así es como lo describe Barthes:

5. Kevin Lynch, La imagen de la ciudad, trad. Enrique Luis Revol (Barcelona: Gustavo Gili, 2008 [1960]).

6. Barthes, La aventura semiológica, 265 .

7. Roland Barthes, Barthes, par Roland Barthes (París: Editions Seuil, 1975), I63. 


\section{DOI: https://doi.org/10.22201/iie.18703062e.2021.119.2753}

La ciudad es una escritura; quien se desplaza por la ciudad, es decir, el usuario de la ciudad (que somos todos) es una especie de lector que, según sus obligaciones y sus desplazamientos, aísla fragmentos del enunciado para actualizarlos secretamente. Cuando nos desplazamos por una ciudad, estamos todos en la situación de los I00.00o millones de poemas de Queneau, donde puede encontrarse un poema diferente cambiando un solo verso; sin saberlo, cuando estamos en una ciudad, somos un poco ese lector de vanguardia. ${ }^{8}$

Más adelante añade: "la ciudad es un poema. [...]. Es un poema que despliega el significante, y este despliegue es lo que la semiología de la ciudad debería tratar de aprehender y hacer cantar". ${ }^{9}$ La ciudad nos lleva a crear continuamente nuevos significados, nuevas combinaciones e interpretaciones de signos, y esta interrelación es infinitivamente valiosa para estimular nuestro lado más creativo.

Josep Cerdà, director de la Maestría en Arte Sonoro de la Universidad de Barcelona, también afirma que "la ciudad es un texto con infinitas posibilidades de lectura", ${ }^{\text {ro }}$ una realidad donde lo inmaterial y emocional impregnan lo físico al conferirle significado. Escribe Cerdà: "una de las funciones del artista es mostrar esta visión diferencial de la realidad". El artista es así el paseante-poeta por antonomasia. A este propósito mencionamos brevemente la importancia de la literatura en la percepción de la ciudad y en particular queremos resaltar la repercusión de las descripciones de los ambientes sonoros urbanos en la formación de una conciencia sonora en la cultura. Por ejemplo, podemos mencionar las descripciones que hace Víctor Hugo en el Jorobado de Notre Dame o en Los Miserables, así como su poesía enteramente dedicada a los sonidos percibidos citada por Michel Chion. ${ }^{\text {II }}$ De igual manera, es destacable en este contexto la descripción de Dublín por James Joyce en el Ulises, la de Buenos Aires de Jorge Luis Borges, la de París de Julio Cortázar o la de Nueva York de Federico García Lorca. El sugerente libro de Italo Calvino, Las ciudades invisibles, ${ }^{12}$ es un magnífico ejemplo de cómo la percepción afectiva de una

8. Barthes, La aventura semiológica, 264.

9. Barthes, La aventura semiológica, 266.

Io. Josep Cerdà, "Observatorio de la transformación urbana del sonido: la ciudad como texto, derivas, mapas y cartografía sonora”, Arte y Políticas de Identidad, núm. 7 (2012): I43-162 https://revistas.um.es/reapi/article/view/I740II (consultado el 9 de febrero de 202I).

II. Michel Chion, El sonido. Música, cine literatura..., trad. Enrique Folch González (Barcelona: Paidós, 1999), 22.

I2. Italo Calvino, Las ciudades invisibles (Madrid: Siruela, 2020). 
ciudad inspira el imaginario. Por último, no podemos dejar de mencionar a Georges Perec quien nos deleita con sus textos dedicados a la percepción de lo urbano, como por ejemplo Tentative d'épuisement d'un lieu parisien ${ }^{13}$ (Tentativa de agotamiento de un lugar parisino) en el que intenta anotar todos los infinitos estímulos perceptivos de un lugar urbano para revelar todo lo que normalmente no percibimos de forma consciente, pero que sí compone la atmósfera emocional de los espacios. El artista Eric La Casa realizó para el Museo de Arte Contemporáneo de Barcelona una obra sonora inspirada en este libro. ${ }^{14}$

\section{La ciudad lúdica}

Este lado poético, lúdico, placentero de la ciudad es lo que la movilidad funcional anula y lo que el urbanismo sensorial quiere hacer revivir. Fue puesto de manifiesto inicialmente por Dada cuando en I92I organizaron la primera visita "banal" de la ciudad como un acontecimiento artístico. Por primera vez la ciudad en sí misma se considera una obra de arte, pero no como objeto sino como lugar, espacio, escenario de posibles experiencias estéticas. A los dadaístas siguieron los surrealistas que fueron los primeros en nominar el inconsciente de la ciudad. Ellos detectaron algo que emanaba de las calles y que no era visible, ni medible, ni nombrable, ni tangible. Descubrieron así que la ciudad, el espacio, es un ser vivo con el que el ser humano interactúa a diario, no es algo inerte que se extiende ante nosotros y que podemos simplemente medir para conocer las coordenadas de nuestra posición. Es mucho más que eso. Es parte de nuestro imaginario y lo que estimula nuestro ser espacial y sensorial.

Estos enfoques fueron retomados por Henri Lefebvre que extendió las ideas surrealistas a la política social y llegó a formular, en su libro La Production de l'espace (La producción del espacio), ${ }^{\text {Is }}$ una propuesta política centrada

13. Georges Perec, Tentative d'épuisement d'un lieu parisien (París: Christian Bourgois éditeur, 2020).

I4. Eric La Casa, Tentative d'épuisement (sonore) d'un lieu parisien (Museo de Arte Contemporáneo de Barcelona, Macba, 23 de abril de 20r6), https:/www.macba.cat/es/ exposiciones-actividades/actividades/tentative-depuisement-sonore-dun-lieu-parisien (consultado el 9 de febrero de 202I).

15. Henri Lefebvre, La Production de l'espace (París: Anthropos, 1974) disponible también en L'Homme et la Société, Sociologie de la Connaissance Marxisme et Anthroplogie, núms. 3I-32 (1974): 15-32, https://doi.org/IO.3406/homso.1974.I855 (consultado el I2 de agosto de 2020). 


\section{DOI: https://doi.org/10.22201/iie.18703062e.2021.119.2753}

en el derecho a la ciudad y al espacio social. Sus ideas germinaron en el movimiento conocido como Internacional Situacionista cuyo principal representante, Guy Debord, vio la necesidad de despertar el lado lúdico y creativo de los ciudadanos impulsando una relación emocional con la ciudad que expresó con mapas psicogeográficos. Para Debord el capitalismo ha dado lugar a la Sociedad del espectáculo, título de su conocido libro, ${ }^{16}$ es decir, una sociedad basada en la representación, donde los ciudadanos, reducidos a la condición de espectadores pasivos, toman la representación por realidad, la creen más real que sus propias necesidades y así viven como marionetas en un sistema que los tiene dominados desde la médula de sus deseos. La estrategia de Debord es la de volver a la vida real, crear "situaciones" lúdicas y poéticas, "Multiplicar los objetos y los sujetos poéticos [...] y organizar los juegos de estos sujetos poéticos entre objetos poéticos" ${ }^{17}$ Se trata de exaltar el lado poético del espacio y de sus transeúntes, de rescatar lo emocional de la ciudad, de ir más allá de la predominancia del sentido de la vista, de superar el papel de meros espectadores para asumir plenamente el de actores, y buscar la "polyphonie des sens" (polifonía de los sentidos) de la que habla Bachelard, ${ }^{18}$ quien nos invita a entablar una relación activa, animista y de amistad con el ambiente que nos rodea. En su fascinante libro La poétique de l'espace (La poética del espacio), nos revela el lado emocional, soñado, amado y vivido del espacio, al enfatizar toda su carga poética y distinguirlo del espacio aséptico geométrico. Escribe Bachelard: "El espacio capturado por la imaginación no puede permanecer como espacio indiferente entregado a la medida y reflexión del geómetra. Es un espacio vivido". ${ }^{19}$ Es el espacio de la interacción simbólica del hombre con el ambiente, donde percibimos la "musique des sens" (música de los sentidos), como escribe Marie-Pierre Lassus, estudiosa de Bachelard, que destaca lo musical inherente en la experiencia de percibir nuestro entorno, cuando nos

16. Guy Debord, La Société du spectacle (París: Editions Champ Libre, 1971).

17. "Multiplier les objets et les sujets poétiques [...] et organizer les jeux de ces sujets poétiques parmi ces objets poétiques", en Guy Ernest Debord,"Rapport sur la Construction des situations et sur les conditions de l'organisation et de l'action de la tendance situationniste internationale", Inter, núm. 44 (verano de 1989): I-II. https://id.erudit.org/iderudit/46876ac (consultado el I2 de agosto de 2020).

I8. Gaston Bachelard, La Poétique de la rêverie (París: Puf, 1960), 6.

19. "L'espace saisi par l'imagination, ne peut rester l'espace indifférent livré à la mesure et à la réflexion du geomètre. Il est vécu", en Gaston Bachelard, La Poétique de l'espace (París: Puf, I957), I7. 
dejamos invadir por los sonidos que percibimos ya no como fenómenos sino como posibilidades que emergen en el silencio de nuestra imaginación. Entonces nos entregamos al sentire italiano, término que en este idioma significa tanto percibir como escuchar, según la pertinente observación de la autora. ${ }^{20}$

\section{Percepción sonora del espacio. Estética sensorial $y$ arquitectura de los sentidos}

Desde múltiples pensadores va avanzando la necesidad de recuperar un enfoque corporal y sensorial en nuestra relación con el espacio circundante. El filósofo Gernot Böhme recupera el sentido original de la palabra estética al señalar que su etimología en griego viene de aisthánesthai que significa percepción, lo que demuestra su original significado de experiencia perceptiva que involucra a todos los sentidos y, a partir de este concepto, ha desarrollado una peculiar teoría estética de la atmósfera, que define como ese algo que engloba objeto y sujeto y que es, además, tanto objetivo, porque está fuera del sujeto, como subjetivo, porque sin sujeto no puede existir. ${ }^{21}$

$\mathrm{El}$ arquitecto finlandés Juhani Pallasmaa recalca la importancia de un enfoque fenomenológico en arquitectura que involucre la participación de todos los sentidos en el gozo de la experiencia corporal dentro del espacio. Critica la primacía del sentido de la vista, lo que define como "el ocularcentrismo y la violación del ojo", ${ }^{22}$ que nos ha llevado a una relación más abstracta y fría con nuestro entorno, y afirma la necesidad de recuperar todos los otros sentidos $y$, en general, volver a un modo más háptico de vivir en el que nos acercamos al mundo y nos sumergimos en sus elementos al dejarnos invadir por el flujo de sensaciones que nos estimulan. Para Pallasmaa todos los sentidos son importantes y todos (incluida la vista), derivan principalmente del tacto que es, escribe citando al antropólogo Ashley Montagu, la "madre de todos los senti-

20. Marie-Pierre Lassus, "Mésologie, musique et musique des sens", http://ecoumene. blogspot.com/20I4/o5/allegory-of-music-frans-floris-de.html (consultado el I2 de agosto de 2020).

2I. Gernot Böhme, "Acoustic Atmospheres. A Contribution to the Study of Ecological Aesthetics", trad. Norbert Ruebsaat, The Soundscape Journal I, núm. I (2000): I4-I8, https:// www.wfae.net/journal.html (consultado el I2 de agosto de 2020).

22. Juhani Pallasmaa, Los ojos de la piel. La arquitectura y los sentidos, trad. Moisés Puente (Barcelona: Editorial Gustavo Gili, 2006), 17. 


\section{DOI: https://doi.org/10.22201/iie.18703062e.2021.119.2753}

dos". ${ }^{23}$ En su libro Los ojos de la piel, Pallasmaa dedica un capítulo a cada uno de los sentidos, muestra su significancia en arquitectura y en nuestra relación con el espacio. El sentido del oído ocupa un papel fundamental en su concepción fenomenológica de la arquitectura, como señalamos más detalladamente en el siguiente apartado.

La relación entre arquitectura y sonido ha sido una constante a lo largo de los siglos. Recordemos la extraordinaria acústica de los teatros y circos de la Grecia y Roma clásicas, las investigaciones centradas en la acústica de los renacentistas Atanasio Kircher ${ }^{24}$ y Robert Fludd, ${ }^{25}$ o los interiores de los templos barrocos, cuyas estructuras arquitectónicas potencian la sonoridad de su espacio. En la arquitectura contemporánea, el urbanismo sensorial es una corriente cada vez más en auge que advierte de forma creciente las limitaciones del urbanismo funcionalista. En este artículo, por evidente falta de espacio sólo hemos podido nombrar a Lynch, Radicchi y Pallasmaa, aunque somos conscientes de la importancia de este tipo de investigaciones dentro de la rama fenomenológica de la arquitectura, con representantes como Aulis Blomstedt (maestro de Pallasmaa), Richard Neutra, Peter Zumthor, Alberto Pérez-Gómez, Steven Holl, Bernard Leiter o el polifacético músico, arquitecto e ingeniero Iannis Xenakis, por citar sólo algunos, cuyas propuestas destacan el componente emocional, sensorial y poético del espacio.

\section{Ver con los oidos}

Para Pallasmaa, el oído es un sentido que nos hace sentir de nuevo en el centro del cosmos contrariamente a la vista que nos separa. Escribe: "La vista aísla mientras que el sonido incluye; la vista es direccional mientras que el sonido es omnidireccional. El sentido de la vista implica una exterioridad, pero el sonido crea una sensación de interioridad" ${ }^{26} \mathrm{El}$ autor subraya la importancia del oído en la percepción y comprensión del espacio por su capacidad de

23. Ashley Montagu, Touching: the Human Significance of the Skin (Nueva York: Harper \& Row, 1986), 3, citado en Pallasmaa, Los ojos de la piel, Io.

24. Joscelyn Godwin, Athanasius Kircher's Theatre of the World (Londres: Thames \& Hudson, 2009).

25. William H. Huffman, Robert Fludd and the End of the Renaissance (Londres: Routledge, I988).

26. Pallasmaa, Los ojos de la piel, 50. 
hacernos percibir la continuidad y profundidad espacial. Con la percepción sonora nos adentramos en el ambiente y sentimos nuestra presencia física en él, al mismo tiempo que percibimos la fisicidad del ambiente al entrar en nosotros. El sonido es siempre cercano, como explica de manera muy sugerente Pallasmaa: "La vista es el sentido del observador solitario mientras que el oído crea una sensación de contacto y solidaridad; nuestra mirada vaga solitaria por las oscuras profundidades de una catedral, pero el sonido del órgano nos hace experimentar de inmediato nuestra afinidad con el espacio." ${ }^{27}$

El sentido del oído tiene la particularidad de hacernos sentir la continuidad de nuestro yo interior fusionado con el espacio exterior. Quizá sea el único sentido que nos hace percibir nuestro cuerpo en sí mismo como un espacio, una caja de resonancia donde reverberan los sonidos exteriores, al entrar en sintonía con sonidos memorizados y tocar fibras sensibles. Los sonidos escuchados a lo largo de nuestra vida constituyen un patrimonio de una gran riqueza emocional que parece imborrable en el tiempo. Estudios neurocientíficos intentan descifrar el misterio del porqué los enfermos de Alzheimer mantienen una memoria musical y, conforme la enfermedad avanza, olvidan todo, pero siguen recordando sus canciones favoritas. ${ }^{28}$

Otra peculiaridad del sentido del oído es su capacidad de percibir la distancia espacial. "El sonido mide el espacio y hace que su escala sea comprensible. Con nuestros oídos acariciamos los límites del espacio", escribe Pallasmaa. ${ }^{29}$ Percibimos la profundidad de la noche oyendo sonidos lejanos o la inmensidad del mar al escuchar el sonido de las gaviotas. El sonido nos da información sobre la distancia al ofrecernos una percepción intuitiva de nuestra posición espacial.

Igualmente, el sentido del oído nos aporta infinitas informaciones sobre la percepción del tiempo, como muestra el geógrafo finlandés Johannes Gabriel Granö, quien afirma que los sonidos son los que más información pueden darnos sobre fenómenos temporales como el tiempo estacional y el ritmo o cadencia. Granö elaboró un peculiar enfoque fenomenológico de la geografía. Como explica Antonella Radicchi, ${ }^{30}$ amplió el objeto de la geografía al ambiente humano entendido de forma holística como el conjunto de los

27. Pallasmaa, Los ojos de la piel, 52.

28. Miguel Ángel Criado, "El alzhéimer no puede con la música”, El País, secc. Neurociencia, 25 de junio de 2015, https://elpais.com/elpais/2015/06/23/ciencia/I435064927_042235.html (consultado el I4 de agosto de 2020).

29. Pallasmaa, Los ojos de la piel, 52.

30. Radicchi, Sull'immagine sonora della città, 32-33. 


\section{DOI: https://doi.org/10.22201/iie.18703062e.2021.119.2753}

fenómenos y de los objetos percibidos por los sentidos. Esta perspectiva sensorial de la geografía lo llevó a formular dos conceptos muy novedosos: por un lado, asemejó la geografía al arte y, por otro, diferenció, en nuestra actividad perceptiva, entre la lejanía y la cercanía, al mostrar cómo la primera se relaciona con el sentido de la vista y la segunda con el oído y el olfato. Ambas actividades se entrelazan para dar lugar a nuestra percepción del paisaje. Granö destacó la importancia del sonido en la percepción de la cercanía espacial e incluyó en sus mapas los elementos sonoros del paisaje que consideró como una información de suma importancia. Clasificó los sonidos y los ordenó según el tiempo y la frecuencia (sonidos estacionales, anuales, esporádicos, etc.) y los diferenció entre naturales (viento, cascadas, pájaros, etc.) y artificiales (voces humanas, ruidos de tráfico, industrias, etc.). ${ }^{31}$ Llama la atención que esta metodología elaborada en 1929 no haya trascendido y esté más generalizada en la elaboración de mapas, lo que demuestra, una vez más, la poca consideración conferida al sonido como fuente de información y de experiencia estética. El interés por la cartografía sonora sólo resurgió con el nacimiento de la nueva geografía humanística americana en los años setenta y con los estudios sobre el sonido del World Soundscape Project impulsado por el compositor R. Murray Schafer, como veremos más adelante. En el ámbito del urbanismo, la cartografía sonora apareció primero y exclusivamente como noise maps (mapas de ruidos), con el objetivo de señalar las zonas de contaminación acústica, ignorando por completo el potencial positivo del ambiente sonoro para el ser humano que será revindicado por el urbanismo de enfoque fenomenológico y sensorial.

\section{Paseo sonoro. Breve guía para un paseo sonoro}

Para el arquitecto o el urbanista deseoso de ir más allá del formalismo funcional y de recuperar nuestras facultades sensoriales, pasear ha sido siempre el medio más idóneo de conocimiento y apreciación porque involucra todos los sentidos e implica una experiencia que se despliega de forma espacio-temporal. Como escribe Antonella Radicchi en su breve guía sobre el paseo sonoro, "A Pocket Guide to Soundwalking": ${ }^{2}$

3I. Johannes Gabriel Granö, Pure Geography (Baltimore: Johns Hopkins University Press, I997 [I929]), I27.

32. Antonella Radicchi, "A Pocket Guide to Soundwalking. Some introductory notes 
Experimentar el espacio caminando en él siempre ha sido un punto de referencia para el arquitecto-urbanista que no sólo está interesado en la forma física de la ciudad, sino también en entender cómo la gente experimenta los espacios de la vida cotidiana, cómo los percibe y qué valores y significados les atribuye. ${ }^{33}$

Se trata de investigar la ciudad desde una óptica cualitativa de búsqueda de valor y significado en la relación ciudadano/ciudad. La autora identifica el paseo sonoro como la mejor herramienta para desarrollar un enfoque plurisensorial en la planificación urbana, y parte de una inmersión perceptiva global que va más allá de la exclusividad visual. Así lo explica: "Los paseos sonoros pueden ser considerados como una de las herramientas más apropiadas para el análisis y la evaluación de la ciudad empezando por la relación perceptiva entre los habitantes y la propia ciudad a través de su ambiente sonoro." ${ }^{34}$

En esta breve guía, Antonella Radicchi nos ofrece una visión general de los varios métodos de paseos sonoros (incluido el suyo) utilizados por artistas, urbanistas, escritores, educadores, urbanistas y arquitectos, organizados por tipos de lugar, duración del paseo, número y particularidades de los participantes, tipos de caminos, actividad o pasividad del paseante, interacciones grupales, puntos señalados, equipamiento técnico, objetivos (cívicos, políticos, educativos, investigativos). Ofrece ejemplos y, para cada uno de los objetivos, sugiere instrucciones. Además de estas útiles informaciones, concluye recalcando que la finalidad última del paseo sonoro es la atenta escucha del ambiente sonoro para percatarnos de su infinita riqueza social y cultural, importantísima para la construcción de nuestra identidad, nuestra memoria y nuestro imaginario colectivo. Nos hacemos así conscientes de la necesidad de protegerlo y de evi-

on its origin, established methods and four experimental variations", en A. Besecke, J. Meier, R. Pätzold y S. Thomaier, eds. Perspectives on urban economics/Stadtökonomie Blickwinkel und Perspektiven (Berlín: Universitätsverlag der TU Berlin, 20I7), 70-73, http:// www.antonellaradicchi.it/wp-content/uploads/2020/o2/Radicchi-2017-A-Pocket-Guide-toSoundwalking.pdf (consultado el I4 de agosto de 2020).

33. "Experiencing space by walking through it, has always been a point of reference for the architect-urbanist who is not merely fascinated by the physical form of the city, but also by understanding how common people experience the spaces of everyday life, how they perceive them and what values and meanings are attributed to them", en Radicchi, "A Pocket Guide to Soundwalking", 70 .

34. "Soundwalks can be seen as one of the most appropriate tools to allow for analysing and evaluating the city starting from the perceptual relationship between the inhabitants and the city itself through its sonic component", en Radicchi, "A Pocket Guide to Soundwalking", 70. 


\section{DOI: https://doi.org/10.22201/iie.18703062e.2021.119.2753}

tar su desaparición, bien por desvanecimiento o por superposición de contaminaciones acústicas industriales y comerciales, originadas por fenómenos de masificación, gentrificación y globalización. El paseo sonoro es, por tanto, una útil herramienta introducida en arquitectura y urbanismo proveniente del campo artístico. A continuación, recordamos brevemente cómo nació y algunos de los artistas más representativos que practican el soundwalking o paseo sonoro.

\section{Soundwalking, meditación en movimiento}

El soundwalking es una práctica artística y de investigación que consiste en caminar centrando la atención en la escucha. Este hecho en apariencia intrascendente, puede producir en quien lo practica un profundo impacto, pues permite, a través de los sentidos, establecer un intenso diálogo entre los sonidos que están dentro de nosotros - la voz de nuestro pensamiento- y los sonidos del mundo.

El compositor e investigador francés Michel Chion, al referirse a esta voz interior, indica: "se la priva de toda reverberación y se oye muy de cerca $[\ldots]$ y al mismo tiempo, toma totalmente posesión del espacio diegético: completamente interna e invadiendo a la vez todo el universo". ${ }^{35}$ Está dentro de nosotros y sin embargo tiene una presencia determinante en la escena narrativa que estamos viviendo con nuestro cuerpo.

En este sentido, encontramos grabaciones de paseos sonoros, donde además de los sonidos ambientales característicos de un determinado entorno, es posible escuchar los sonidos emitidos por el cuerpo del caminante. Las huellas de su respiración o el crujir de las hojas bajo la presión de sus pisadas son el indiscutible testimonio de la singularidad de cada individuo y de la presencia de esta voz o espacio interior. Así, la resonancia de nuestro cuerpo se mezcla con el entorno, dando lugar a una vibración plagada de matices y resonancias, el rumor del mundo.

La expresión soundwalking se utilizó por primera vez por los miembros del World Soundscape Project (wsP) — Proyecto Mundial de Paisaje Sonoro-, con la dirección del compositor R. Murray Schafer en la Universidad Simon Fraser de Canadá, en la década de los años setenta. Forma parte de una inves-

35. Michel Chion, La audiovisión: introducción a un análisis conjunto de la imagen y el sonido, trad. Antonio López Ruiz (Barcelona: Paidós, 2008), 8I. 
tigación más amplia sobre los paisajes sonoros, soundscapes, llevada a cabo por R. Murray Schafer y otros integrantes de su equipo en esta misma época; uno de sus objetivos principales fue establecer una metodología que permitiese "afinar el mundo", línea argumental y motivo vertebrador de la conocida publicación de Murray Schafer, El paisaje sonoro y la afinación del mundo, ${ }^{36}$ donde las conexiones existentes entre el comportamiento del sonido, el oyente y el medio, se plantean como un sistema de relaciones, y no como realidades independientes.

$\mathrm{Al}$ retomar el tema que nos ocupa, el surgir del soundwalking, y anticipándonos a la convergencia entre las artes que abordaremos más adelante, observamos que tanto el land art como el soundwalking son movimientos cuyo nacimiento coincide en el tiempo. Si desde las artes visuales el land art establece un diálogo entre individuo y naturaleza, al renunciar a las galerías y museos como lugar para exhibir la obra, también el soundwalking se aleja de la sala de conciertos, y propone el caminar y la escucha como acto creativo de conocimiento y transformación simbólica, tanto del espacio como del caminante.

Los investigadores del wsp —actualmente World Forum for Acoustic Ecology (Foro Mundial de Ecología Acústica) — interpretan el paseo sonoro como aquel en el que se atiende a diferentes perspectivas (medioambiental, antropológica, física o musical), en el cual se adopta la práctica de escuchar el espacio recorrido como experiencia estética y como herramienta de investigación de las características sónicas de un lugar. Puede realizarse individualmente o en grupo, ańadir el sonido de la voz a la experiencia, ser grabado o no, reubicarse en el mismo lugar una vez grabado o, por el contrario, llevarse a otros espacios.

Con estas directrices han surgido publicaciones germinales sobre el tema; en uno de estos textos, publicado por primera vez en 1974, la compositora e investigadora Hildegard Westerkamp describe el paseo sonoro como: "Cualquier excursión cuyo propósito principal es escuchar el medio ambiente", ${ }^{37}$ y sugiere que, para empezar, es mejor limitar el área para incrementar la intensidad: "El primer paseo sonoro se puede hacer en cualquier lugar, en cualquier momento

36. R. Murray Schafer, The Tuning of the World (Nueva York: Knopf, 1977), en español: R. Murray Schafer, El paisaje sonoro y la afinación del mundo, trad. Vanesa García Cazorla (Barcelona: Intermedio, 2013).

37. "Any excursion whose main purpose is listening to the environment", en Hildegard Westerkamp, "Soundwalking", en Autumn Leaves, Sound and the Environment in Artistic Practice (París: Angus Carlyle, 2007), 49, https:/www.hildegardwesterkamp.ca/writings/ writingsby/?post_id=I3\&title=soundwalking (consultado I4 de agosto 2020). 


\section{DOI: https://doi.org/10.22201/iie.18703062e.2021.119.2753}

y con la frecuencia que se desee. En aras de la intensidad, es aconsejable limitar inicialmente el paseo a un área pequeña o incluso a un punto en particular." ${ }^{8}$

Desde un enfoque técnico, Westerkamp alterna en sus propuestas lo reconocible y lo transformado. Por una parte, valora los sonidos en sí mismos, como hechos autorreferenciales que configuran el carácter de un lugar por medio de su representación acústica y, por otra, manipula y transforma esos sonidos para volverlos a incorporar al medio. Con esta doble estrategia (utilizada posteriormente por muchos autores), los sonidos transformados se aproximan a un espacio de ficción que potencia la cualidad real de los demás acontecimientos. Como explica la compositora: "Estos sonidos son usados en parte como ocurren en la realidad y en parte como objetos sonoros transformados en estudio. Se crea una oscilación continua entre los paisajes sonoros reales e imaginarios, entre los lugares reconocibles y transformados, entre la realidad y la composición." ${ }^{9}$

No podemos dejar de mencionar en este texto los paseos diseñados por la recientemente desaparecida Andra McCartney, algunos de ellos realizados en colaboración con Westerkamp, cuyo trabajo también profundizó en la experiencia y el significado de la audición. El blog creado por ella, "Soundwalking Interactions", ${ }^{40}$ sigue siendo un significativo recurso en línea sobre su método de estudio del paisaje sonoro y la participación del público. El objetivo de su proyecto es mostrar el potencial del paseo sonoro que representa al mismo tiempo una forma de creación y un método de investigación, el cual utiliza la escucha y la grabación de sonidos de un territorio explorado a pie y anima al público a la abierta participación. Así lo explica la artista:

Cada sonido puede ser considerado de manera musical, como instrumento mnemónico, o como fuente de información sobre el ambiente. Los sonidos

38. "The first soundwalk can be done anywhere, at any time, and as often as desired. For the sake of intensity, it may be wise to limit the walk initially to a small area or even to one particular spot", en Westerkamp, "Soundwalking".

39. "These sounds are used partly as they occur in reality and partly as sound objects altered in the studio. A continuous flux is created between the real and imaginary soundscapes, between recognizable and transformed places, between reality and composition", en Hildegard Westerkamp, "A Walk through the City", https:/www.hildegardwesterkamp.ca/sound/ comp/3/walkcity/ (consultado el I4 de agosto de 2020).

40. Andra McCartney, Soundwalking Interactions, https://soundwalkinginteractions. wordpress.com (consultado el I4 de agosto de 2020). 
concretos pueden servir de punto de partida para una conversación uniendo las dimensiones epistemológicas, estéticas y éticas de los lugares que ocupan. ${ }^{41}$

Pero escuchar no es oír, requiere de nuestra voluntad y atención; implica comprender, descifrar lo que ya hemos oído, redescubrir y movilizar nuestra conciencia. Por este motivo, Westerkamp concibe el paseo sonoro como una ósmosis entre el yo y el mundo, una actividad multisensorial donde se demanda la concentración y reflexión del caminante que deberá estar inmerso en la práctica con todos sus sentidos, participando, formando parte y "sonando" con el trayecto. Su propuesta es pues, una meditación en movimiento, a cuya larga tradición en las historias del caminar se han referido escritores caminantes como Henry David Thoreau o David Le Breton, quienes desvelan la sacralidad intrínseca al acto de caminar. Thoreau, en su famoso libro Caminar, explica que el término inglés saunterers — que significa "caminantes" - proviene del francés "Sainte Terre", porque así es como se empezaron a nombrar a los peregrinos. Esta alusión a la Tierra Santa es muy apropiada, ya que, para Thoreau, "cada caminata es una especie de cruzada", ${ }^{42}$ que nos hace percibir y apreciar lo "sagrado" de la naturaleza. De igual manera, el antropólogo David Le Breton, que ha elogiado la marcha en numerosas publicaciones, insiste en el estado meditativo y sagrado en el que entramos al caminar. Así lo expresa en su último libro: "Cada paseo comienza como una caminata, pero gradualmente se convierte en una peregrinación. [...] Lo sagrado reside en el movimiento mismo del caminar, su progresión, el encanto que engendra." ${ }^{43}$

4I. "Chaque son peut y être considéré de façon musicale, comme outil mnémonique, ou bien comme source d'information sur l'environnement. Les sons concrets recueillis peuvent servir de point de départ à une conversation liant les dimensions épistémologiques, esthétiques et éthiques des lieux qu'ils remplissent”, en Andra McCartney, Soundwalking Interactions, https://soundwalkinginteractions.wordpress.com/francais/ (consultado el is de agosto de 2020).

42. "Every walk is a sort of crusade", en Henry David Thoreau, "Walking", en The Writings of Henry David Thoreau (Boston y Nueva York: Houghton Mifflin and Company, 1906), 205248, https://www.walden.org/web/viewer.html?file=; https:/www.walden.org/wp-content/ uploads/2016/03/Walking.pdf (consultado el I7 de agosto de 2020).

43. "Toute marche commence en randonnée mais se mue peu à peu en pèlerinage. [...] Le sacré réside dans le mouvement même de la marche, sa progression, l'enchantement qu'elle engendre", en David Le Breton, Marcher la vie: Un art tranquille du bonheur (París: Edition Métailié, 2020), pos. 897, Kindle. 


\section{DOI: https://doi.org/10.22201/iie.18703062e.2021.119.2753}

Abrir la percepción, concentrarnos y trabajar la escucha, se relaciona también con la apreciación de los "Indices Sonores Matérialisants" (indicios sonoros materializantes) (ISM), expresión utilizada por el compositor e investigador Michel Chion para designar "un aspecto del sonido, el que sea, que nos permite apreciar la naturaleza material de su fuente y la historia concreta de su emisión: su naturaleza sólida, aérea o líquida, su consistencia material, los accidentes ocurridos durante su desarrollo, etc." ${ }^{44}$

Considerar los ruidos cercanos, tratar de identificar los que se producen más lejos, distinguir la presencia de los graves — como indicio de algo pesado y voluminoso-, tener en cuenta el ritmo, la repetición, la duración, etc., en resumen, tratar de detectar cada elemento del espectro acústico, nos permitirá vivir la experiencia del paseo sonoro con toda su riqueza. Marshall McLuhan nos recuerda al respecto: "No existen límites para el sonido. Escuchamos desde todas las direcciones en un mismo instante, pero el balance entre nuestra experiencia interna y externa puede ser preciso [...]. El sonido viene desde arriba, abajo, de los lados [...] pasa a través de nosotros y raramente está limitado por la densidad de los objetos físicos". ${ }^{45}$

Proseguiremos este escrito examinando varios enfoques contemporáneos de la práctica del paseo sonoro.

\section{Convergencias creativas imagen/sonido: espacio, cuerpo y percepción}

Sabemos que la separación de géneros artísticos entre lo estático y lo dinámico —establecida por G. H. Lessing ${ }^{46}$ como artes del espacio (plásticas) y artes

44. "Un aspect d'un son, quel qu'il soit, qui fait ressentir plus ou moins précisément la nature matérielle de sa source et l'histoire concrète de son émission: sa nature solide, aérienne ou liquide, sa consistance matérielle, les accidents survenant dans son déroulement, etc.", en Michel Chion, Audiovision. Glossaire. Ioo concepts pour penser et décrire le cinéma sonore, 26, http://michelchion.com/texts (consultado el is de agosto de 2020).

45. "There are no boundaries to sound. We hear from all directions at once. But the balance between inner and outer experience can be precise. [...] Sound comes to us from above, below, and the sides [...] it passes through us and is rarely limited by the density of physical objects", en Marshall McLuhan, Visual and Acoustic Space (Londres: Cox Christopher \& Warner D Editores. Audio Culture. Readings in modern music, 2004), 63.

46. Gotthold Ephraim Lessing, Laocoonte o sobre los limites en la pintura y la poesía, trad. Sixto J. Castro (Barcelona: Herder, 20I4). 
del tiempo (música y literatura)—, había dominado el sistema de las artes del clasicismo. Sabemos también que el discurso histórico, especialmente a partir de la Ilustración, había establecido una clara jerarquía de la vista sobre el oído y el resto de las capacidades sensoriales. Sin embargo, esta dicotomía se debilita según avanza el siglo xx cuando el sentido del oído experimenta un interés creciente condicionado por los cambios ideológicos, sociales, tecnológicos y estéticos. Por otra parte, la separación entre artes del espacio y artes del tiempo, adoptada por Lessing, entraría en crisis con las vanguardias, cuando el futurismo reivindique el dinamismo de los cuerpos, el movimiento y la velocidad como valores plásticos. ${ }^{47}$ Quizá esta unión de las artes sea el resultado de un hecho evidente: pues, aunque el sonido exista en el tiempo, se transmite por medio del espacio $y$, a pesar de que las artes visuales habiten el espacio, se transmiten mediante una narrativa temporal.

A partir de la fusión de estos márgenes, son numerosos los artistas que han experimentado con el concepto acústico en la elaboración de su obra plástica. Del mismo modo, artistas sonoros interesados en la psicología de la escucha, las ilusiones auditivas o los efectos psicoacústicos, han colaborado con artistas de diferentes campos para crear obras audiovisuales, instalaciones, performances o piezas de danza. En ocasiones, esta cooperación aparece de manera puntual $y$, otras veces, es un rasgo definitivo. Pero indudablemente, se ha producido un deslizamiento de lo musical a lo plástico y de lo plástico a lo musical. Los creadores han pasado a ser los responsables de seleccionar aquella parte de la naturaleza exterior que debe ser tenida en cuenta, los límites se han diluido y han surgido nuevas formas híbridas de expresión, donde el sonido se ha convertido en objeto-concepto. La creciente interconexión entre artes visivas y sonoras ha ampliado los confines del arte hacia la multiplicidad sensorial, como afirma el profesor y artista sonoro Javier Ariza:

Los diversos discursos estéticos y filosóficos que han introducido el concepto y la materia sonora dentro de la obra plástica contemporánea han sido definitivos para elaborar las bases de un arte plurisensorial. Discursos que han reflexionado sobre el sonido y el silencio, el sonido y el paisaje, el sonido y la escultura, el sonido y su gráfica visual, etc. ${ }^{8}$

47. Richard Humphreys, Futurismo, trad. Mario Schoendorff Rodríguez (Madrid: Encuentro, 2000), 7.

48. Javier Ariza, Las imágenes del sonido: una lectura plurisensorial en el arte del siglo XX (Cuenca: Universidad de Castilla-La Mancha, 2003), I3. 


\section{DOI: https://doi.org/10.22201/iie.18703062e.2021.119.2753}

Utilizaremos este análisis de Javier Ariza como hilo conductor para acercarnos a la obra de artistas como Craig Shepard, Michelle Nagai y Tracy Grubbs que combinan el movimiento corporal y la influencia cardinal del Deep Listening de Pauline Oliveros ${ }^{49}$ en sus propuestas. Deep Listening (escucha profunda) se ha convertido en un método ético y estético para practicar la escucha como forma de expresión artística de enorme trascendencia, que ha influido en la obra de numerosos artistas contemporáneos. Este método, elaborado por la artista y compositora experimental Pauline Oliveros, estimula las capacidades de escucha y amplía nuestra conciencia sonora, al superar el ámbito estrictamente auditivo para abrirnos a una percepción multisensorial y holística, capaz de multiplicar por mil nuestra creatividad, prueba del increíble potencial, a menudo inexplotado, del sentido del oído. Numerosos artistas de todos los campos han sido fuertemente influidos por Oliveros y le siguen rindiendo homenaje en la web "Still listening to Oliveros"so (escuchando todavía a Oliveros) que aúna experimentos musicales del mundo entero.

Antes de aproximarnos al trabajo de estos autores, debemos recordar que, además de la atención en la escucha como práctica creativa, el cuerpo en movimiento ocupa un lugar significativo en el arte sonoro y, en particular, en las variantes del paseo sonoro, donde se impulsa al oyente a estar físicamente activo. El cuerpo, frontera entre el yo y el mundo, es el punto de acceso tanto a la vida exterior como a la interior, como indica Deleuze: "el cuerpo ya no es el obstáculo que separa el pensamiento de sí mismo, lo que tiene que superar para llegar al pensamiento. Es, por el contrario, aquello en lo que se sumerge o debe sumergirse para alcanzar lo impensado, que es la vida". ${ }^{\mathrm{I}}$

El primero de los artistas a los que haremos referencia, Craig Shepard, conjuga en sus piezas el caminar con la escucha profunda del medio. Entre sus obras se incluye On Foot: Switzerland. 3 I days and 250 miles, ${ }^{52}$ para la que cada día componía una nueva pieza que interpretaba al aire libre esa misma noche,

49. Pauline Oliveros, Deep Listening. Una práctica para la composición sonora, trad. Francisco Campillo García (Valencia: Edict Oràlia Música, 2019).

50. Pauline Oliveros, "Still listening Pauline Oliveros", http://stilllisteningoliveros.com/ (consultado el I6 de agosto de 2020).

51. Gilles Deleuze, La imagen-tiempo. Estudios sobre cine 2, trad. Irene Agoff (Barcelona: Paidós, 1986), 25.

52. "A pie: Suiza 3I días y 250 millas", Craig Shepard, On Foot: Switzerland, https:// craigshepard.bandcamp.com/album/on-foot-switzerland (consultado el I6 de agosto de 2020). 


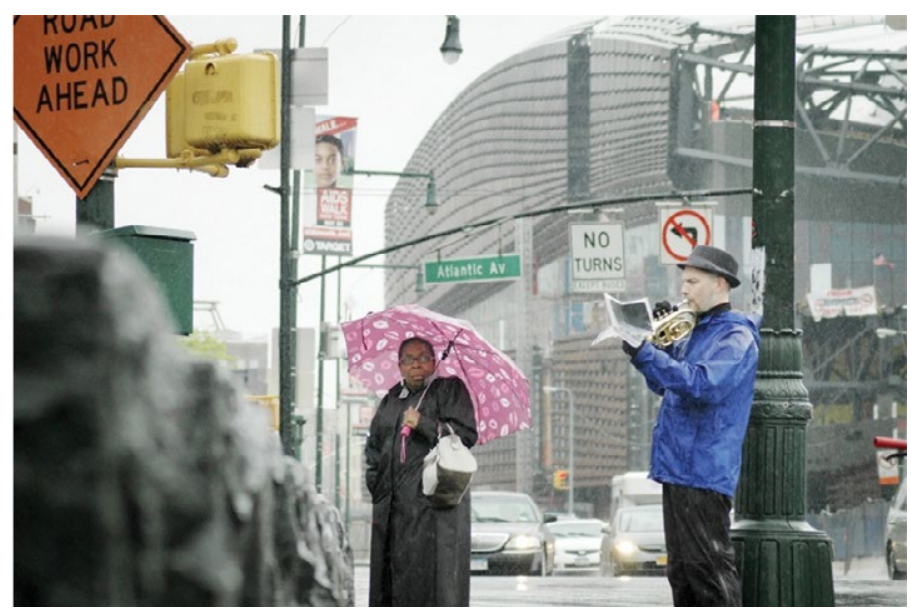

I. Craig Shepard, On Foot: Brooklyn, 20I2, Brooklyn, N.Y. Foto: (C) Beth O’Brien. El artista pasea por la ciudad y ejecuta su pieza musical.

y On Foot: Brooklyn. 9I days. I3 new pieces. 780 miles on foot, ${ }^{53}$ en la que pasea durante 9I días por la ciudad inspirándose de su atmósfera para componer una pieza al final de cada semana y ejecutarla en público (fig. I). En su web $O n$ Foot ${ }^{54}$ explica que el objetivo de sus creaciones musicales es "invitar a la gente a vivir la belleza de los sonidos en los que se mueve en su día a día".ss

Los Extreme Slow Soundwalks (Paseos sonoros extremadamente lentos) también son herederos del legado de Oliveros, realizados por la artista sonora Michelle Nagai en colaboración con la coreógrafa Hope Mohr. Se integran en el proyecto iLAND e iLAB, ${ }^{56}$ un programa de residencia colaborativa entre artistas, científicos, diseñadores urbanos y paisajistas, basado en el movimiento y la comprensión cinética del mundo. Mohr y Nagai fueron seleccionadas para la primera residencia ilab que se celebró del ir al 23 de septiembre de 2006 en la ciudad de Nueva York. En su proyecto, titulado The Language of

53. "A pie: Brooklyn. 91 días. I3 piezas nuevas. 780 millas a pie", Craig Shepard, On Foot: Brooklyn, https://www.onfoot.org/onfootbrooklyn (consultado el I7 de agosto de 2020).

54. Shepard, On Foot, https://www.onfoot.org/ (consultado el I7 de agosto de 2020).

55. "invite people to live in the beauty of the sounds that they move through in their day to day lives", en Shepard, On Foot.

56. iLAB (Interdisciplinary Laboratory), iLAND (Interdisciplinary Laboratory for Art Nature and Dance), http://www.ilandart.org/ilab/ (consultado el I7 de agosto de 2020). 


\section{DOI: https://doi.org/10.22201/iie.18703062e.2021.119.2753}

32 LAURA APOLONIO Y MAR GARRIDO-ROMÁN

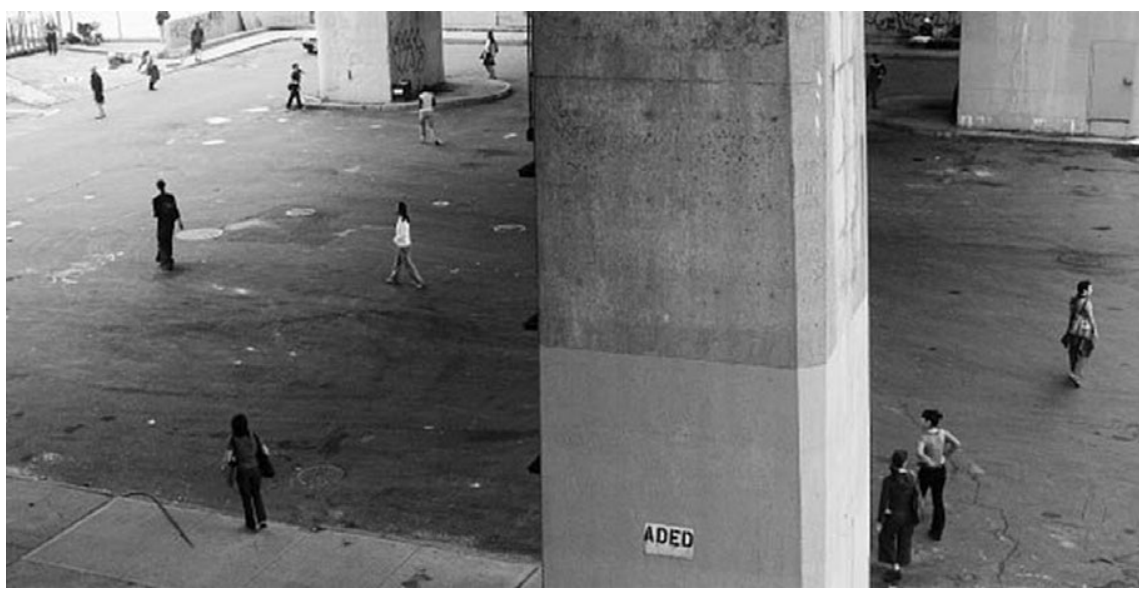

2. Hope Mohr y Michelle Nagai, The Language of the Listening Body, 2006, Long Island City, N.Y. Foto: (C) Ian W. Douglas.

the Listening Body ${ }^{57}$ (El lenguaje del cuerpo que escucha), se invitaba al público - guiado por los bailarines coreografiados por Mohr- a caminar de manera deliberadamente lenta en una ciudad como Nueva York, consumida por la prisa y lo virtual. Al ralentizar el ritmo de la acción, se pretendía vivir la experiencia del caminar como una reflexión acerca de la fisicidad del cuerpo, las sensaciones, los pensamientos y las emociones, para elevar así nuestra conciencia personal (fig. 2).

Esta lentitud extrema de los cuerpos en movimiento es, de igual forma, el argumento seguido por Tracy Taylor Grubbs al realizar — también en colaboración con la coreógrafa Hope Mohr-su pieza Slow Line Feb. 4, 20I5, ${ }^{58}$ donde la lentitud, la atención, el cuidado extremo y lo real se contraponen con la velocidad y lo virtual..$^{99}$ En San Francisco, en plena hora pico, extendieron por la acera un rollo de papel blanco con una longitud de 45 metros sobre el que emprendieron una extraña danza a ras de suelo, en la que se transformaban en las criaturas más lentas de la calle, al dibujar una línea de arabescos que reflejaba

57. Michelle Nagai y Hope Mohr, The Language of the Listening Body, http://www.ilandart. org/ilab/language-of-the-listening-body/ (consultado el I7 de agosto de 2020).

58. Línea lenta, 4 de febrero de 2015.

59. Tracy Taylor Grubbs, The Slow Line Feb. 4, 20I5, https://vimeo.com/120554664 (consultado el ro de julio de 2020). 


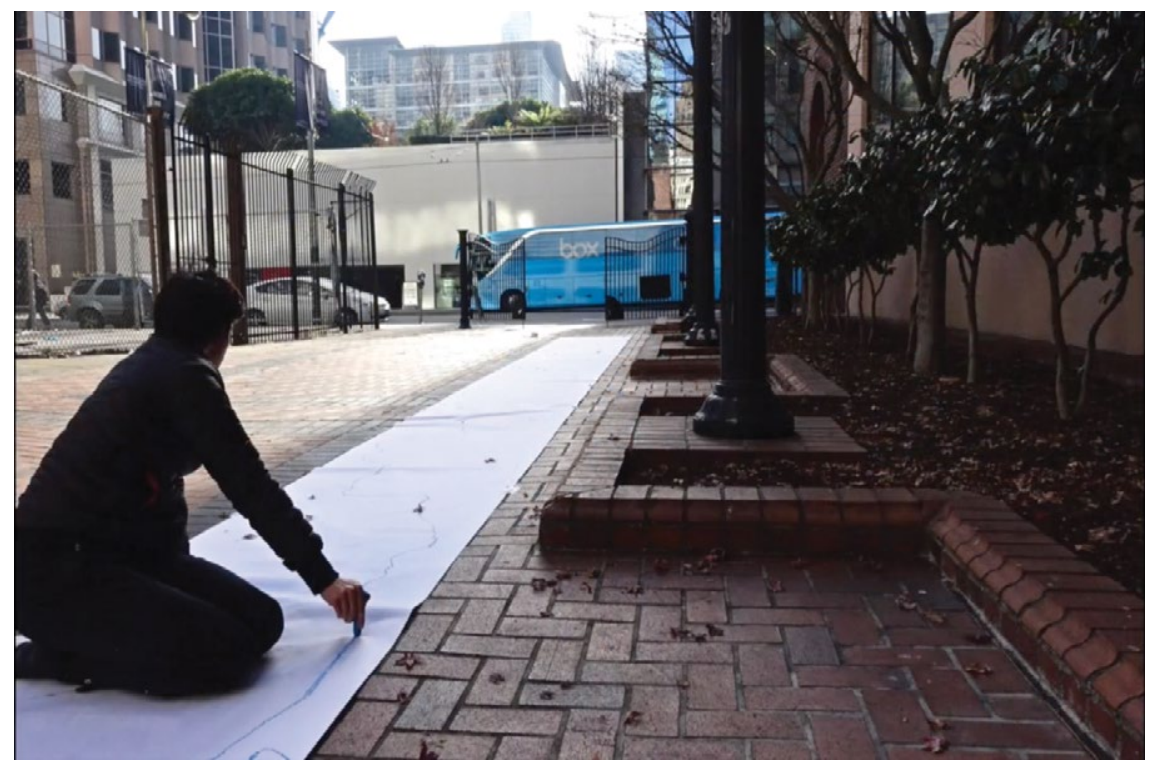

3. Hope Mohr y Tracey Taylor Grubbs, The Slow Line Feb. 4, 2015, San Francisco, California. Foto: (C) Georgia K. Smith.

sus movimientos mientras se arrastraban y gateaban sobre el papel blanco, metáfora de una frontera entre un invisible mundo poético, potencialmente siempre a nuestro alcance, y el utilitario que nos atrapa en la prisa y del que con dificultad conseguimos escapar. "Éramos dos mujeres disfrutando del inútil, pero tan necesario acto de dibujar una línea lenta", explica la artista (fig. 3).$^{60}$

Otras interesantes ramificaciones del soundwalk son los Shadow-walks (paseos en sombra) de Viv Corringham o los Electrical walks (paseos eléctricos) de Christina Kubisch.

Viv Corringham es una artista multidisciplinar cuyo trabajo incluye conciertos, paseos sonoros, radio experimental, performances e instalaciones multicanal. Es internacionalmente conocida por sus proyectos sonoros encargados por festivales como el Drift Sound Art Festival en Escocia; Sirius Arts Center en Irlanda; Place Sound Festival en Melbourne; Sound Art Museum en Roma, San Francisco Art Festival en Estados Unidos; Freedom of the City Festival en

60. "We were two women relishing the useless, but oh- so-necessary act of drawing a slow line", en Tracy Grubbs, The Slow Line (Part I), http://www.tracygrubbs.com/blog/2015/8/4/ the-slow-line-part-I (consultado el I7 de agosto de 2020). 


\section{DOI: https://doi.org/10.22201/iie.18703062e.2021.119.2753}

Reino Unido, o el Encuentro Internacional Walking Practices/Walking Art/ Walking Bodies en Prespes, Grecia, donde tuvimos ocasión de conocerla.

Corringham realiza improvisaciones con la voz en sus Vocal strolls (paseos vocales) ${ }^{6}$ para estudiar las propiedades acústicas del entorno, y explorar la interacción del sonido y el espacio. Como ella misma explica, los paseos vocales, que se convirtieron en un programa habitual en la radio Resonance FM de Londres, consistían en "deambular por la ciudad escuchando el entorno y respondiendo con cantos improvisados" ${ }^{62}$ Inspirada en las songlines ${ }^{63}$ de los aborígenes y en los estudios del antropólogo y etnomusicólogo Steven Feld, ${ }^{64}$ Corringham investiga los vínculos entre caminar, cantar y el sentido del lugar. Discípula del Deep Listening de Oliveros, su punto de partida es la escucha de los sonidos cotidianos, a los que añade las historias locales que le cuentan los habitantes del lugar, inspirándose así para sus propias improvisaciones vocales. Está interesada en estudiar el sentido de cada lugar y cómo éste se vincula con la historia personal y la memoria de sus habitantes. ${ }^{65}$ Continuación de los Vocal strolls y ejemplo paradigmático de su manera de entender los paseos sonoros, son los Shadow-walks (caminatas en la sombra). Un proyecto iniciado en 2003, desarrollado en Canadá, Asia, Europa, América y Australia y que continúa en la actualidad. Corringham detalla en su página web su proceso de trabajo:

Llego a un nuevo lugar y pido a los habitantes locales que me lleven a un paseo especial, uno que hayan repetido muchas veces y que tenga sentido o significado para esa persona. Mientras caminamos juntos, grabo nuestras conversaciones y los sonidos del entorno. Después vuelvo sola por la misma ruta, tratando de sentir las huellas de mi anterior compañero de paseo. Luego canto lo que siento usando improvisaciones sin palabras.

El sonido ambiente, las conversaciones mantenidas y, de nuevo, las improvisaciones vocales, son la materia prima que posteriormente Corringham, en su estu-

6I. Shawn Greenlee, "Constructing Urban Space with Sounds and Music", Public Art Dialogue, 5, núm. I (2015): 106-I07, https://doi.org/I0.1080/21502552.2015.101084I.

62. Viv Corringham, https://www.worldlisteningproject.org/places-and-traces/ (consultado el 17 de agosto de 2020).

63. Bruce Chatwin, The Songlines (Londres: Vintage Digital, 2012), Kindle.

64. Steven Feld, http://www.stevenfeld.net (consultado el I7 de agosto de 2020).

65. Viv Corringham, "Urban Song Paths: Place Resounding”, Organised Sound II, núm. I (2006): 27-35, https://doi.org/IO.IOI7/SI355771806000057. 
dio, selecciona y ecualiza para convertirla en la pieza final, el Shadow-walk. Para la autora es importante que sus Shadow-walks ${ }^{66}$ se escuchen en los lugares donde se hicieron y por las personas que caminaron con ella. Por este motivo y para ampliar su difusión los convierte en audiocaminatas, conciertos, obras de radio (fig. 4), instalaciones de sonido e incluso en una aplicación para el iPhone. ${ }^{67}$

La pandemia de covid-I9 ha obligado a Viv Corringham a variar sus métodos. Ahora, en lugar de acompañar a la persona elegida en su paseo y después repetir e interpretar el camino sintiendo las huellas de la persona ausente, ha utilizado las descripciones grabadas de los caminantes a las que añade improvisaciones vocales inspiradas en cómo imagina estos paseos. Ha llamado a estas obras Shadow-walks (at home), ${ }^{68}$ (caminatas en la sombra [en casa]). Cinco de ellas se emitieron el pasado 30 de junio de 2020 en un programa de radio Resonance FM de Londres.

A continuación, explicaremos los Electrical walks de Christina Kubisch que conducen al oyente a diferentes lugares de la ciudad en los que se puede apreciar una amplia variedad de las emisiones electromagnéticas. Kubisch invita a utilizar un sistema de amplificadores y unos auriculares especiales para explorar estas frecuencias electromagnéticas, en condiciones normales inaudibles, ubicadas en el espacio urbano. ${ }^{69}$

Es razonable pensar que el rango dinámico de estos sonidos, su timbre y su volumen varían de una ciudad a otra y de un país a otro, pues las frecuencias electromagnéticas que generan la obra (sistemas inalámbricos de comunicación, cámaras de vigilancia, teléfonos móviles, etc.) son diferentes en cada lugar.

En los Paseos eléctricos desarrollados por la artista, la transmisión del sonido se consigue mediante bobinas eléctricas integradas en cada uno de los

66. "I arrive in a new place and ask local inhabitants to take me on a special walk, one that has been repeated many times and has meaning or significance for that person. While walking together, I record our conversations and the sounds of the environment. I then go back along the same route alone, trying to get a sense of my previous companion's traces on the walk. Then I sing what I feel using wordless improvisations", en Viv Corringham, Shadowwalks, http://vivcorringham.org/shadow-walks (consultada I7 de agosto de 2020).

67. Viv Corringham, Shadow-walks, en http://vivcorringham.org/shadow-walks.html (consultado el 2I de febrero de 2020).

68. Viv Corringham, Shadow-walks (at home), https://soundcloud.com/ivorringham (consultado el 2I de febrero de 2020).

69. Arnau Horta, Genealogías sonoras (Radio del Museo Reina Sofía, 28 de octubre de 2019), https://radio.museoreinasofia.es/genealogias (consultado el I4 de abril de 2020). 


\section{DOI: https://doi.org/10.22201/iie.18703062e.2021.119.2753}
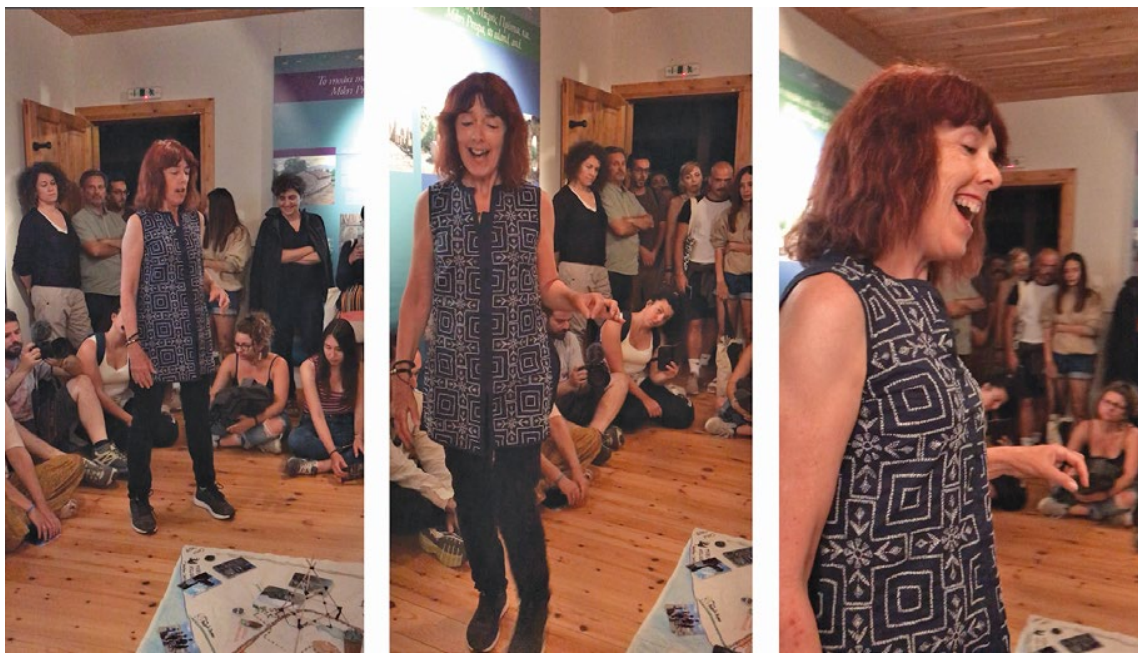

4. Viv Corringham, Shadow-walk in Prespa, 2019, Prespes (Grecia). Foto: (C) Laura Apolonio.

auriculares que responden a las ondas electromagnéticas de nuestro entorno. Arnau Horta, investigador especializado en sonido, lo explica así:

Una de las principales herramientas de grabación que emplea Christina se parece mucho a un sencillo par de auriculares y es también el dispositivo que proporciona al público cuando hace uno de sus paseos electromagnéticos. Estos auriculares cubren ambas orejas, así que su tamaño es parecido al de los cascos de los pilotos de avión o de helicóptero. Pero Christina los ha manipulado de manera muy hábil, introduciendo bobinas eléctricas en cada uno de los auriculares y conectándolas luego a los altavoces que están colocados justo encima de las orejas. ${ }^{70}$

La escucha en movimiento que propone Christina Kubisch utiliza cascos especiales con extensiones sensoriales sensibles a las ondas electromagnéticas para registrar e interpretar las múltiples capas ocultas del entorno urbano. Sus cartografías de la escucha completan y amplían la percepción visual y nos hacen partícipes de dimensiones silenciadas. Estos sonidos que por lo común no oímos son, afirma la artista, sorprendentemente musicales y cuando los escuchamos, cambian para siempre nuestra percepción de la ciudad. Así lo expli-

70. Horta, Genealogías sonoras. 
ca: "La percepción de la realidad de todos los días cambia cuando escuchamos los campos electromagnéticos; la realidad a la que estamos acostumbrados aparece en un contexto diferente. Nada se ve como suena. Y nada suena como parece." ${ }^{71}$ Podríamos decir que sus piezas configuran un escenario mixto, donde los límites entre ficción y realidad se diluyen, situándonos al mismo tiempo adentro y afuera del contexto. Adentro, pues escuchamos mientras caminamos y afuera porque percibimos a través de un dispositivo tecnológico una realidad exterior, aunque invisible (fig. 5).

Esta problemática cuestión del desfase entre la realidad vivida y escuchada nos recuerda los trabajos de soundwalking que se basan en la relación entre la experiencia vivida y el relato de esa experiencia, que es precisamente lo que ha llevado a artistas como Sophie Calle, Mariana Castillo Deball o Janet Cardiff, a construir (valiéndose de audioguías) lugares narrativos que emanan una reflexión sobre la construcción de la identidad, la ficción y la realidad.

Sophie Calle en La Visite Guidée (1994) y Mariana Castillo Deball en Estas ruinas que ves (2006) han utilizado audioguías que trascienden el ámbito didáctico propio de los museos. En la obra de Sophie Calle, los asistentes al Museo Boymans Van Beuningen de Rotterdam escuchaban la voz de la artista ausente que narraba sus recuerdos acerca de una serie de nimios objetos personales - una cama, un cubo de plástico, una cuchilla de afeitar, una taza, etc.- expuestos en las vitrinas junto a otras piezas artísticas pertenecientes a los fondos del museo. La narración autobiográfica escuchada con audioguías transformaba la visita museística en una experiencia escenográfica y generaba una nueva mirada sobre el museo y los objetos históricos expuestos en sus vitrinas. ${ }^{72}$

Por su parte, la obra de Castillo Deball se mueve entre política, historia, patrimonio e identidad, al tratar de encontrar en el presente los vestigios de la práctica arqueológica. El Museo de Arte Carrillo Gil de México albergó el proyecto Estas ruinas que ves, donde piezas del fondo del museo fueron reemplazadas por unos números grandes y dorados - del I al 8o- en vitrinas vacías, que la audioguía describía con 80 relatos correspondientes que, como afirman

7I. "The perception of everyday reality changes when one listens to the electromagnetic fields; what is accustomed appears in a different context. Nothing looks the way it sounds. And nothing sounds the way it looks", en Christina Kubisch, Electrical Walks, http://www. christinakubisch.de/en/works/electrical_walks (consultado el I7 de agosto de 2020).

72. Sophie Calle, La visite Guidée, http://artistsbooksandmultiples.blogspot.com/2012/O2/ sophie-calle-la-visite-guidee.html (consultada el I7 de agosto de 2020). 


\section{DOI: https://doi.org/10.22201/iie.18703062e.2021.119.2753}

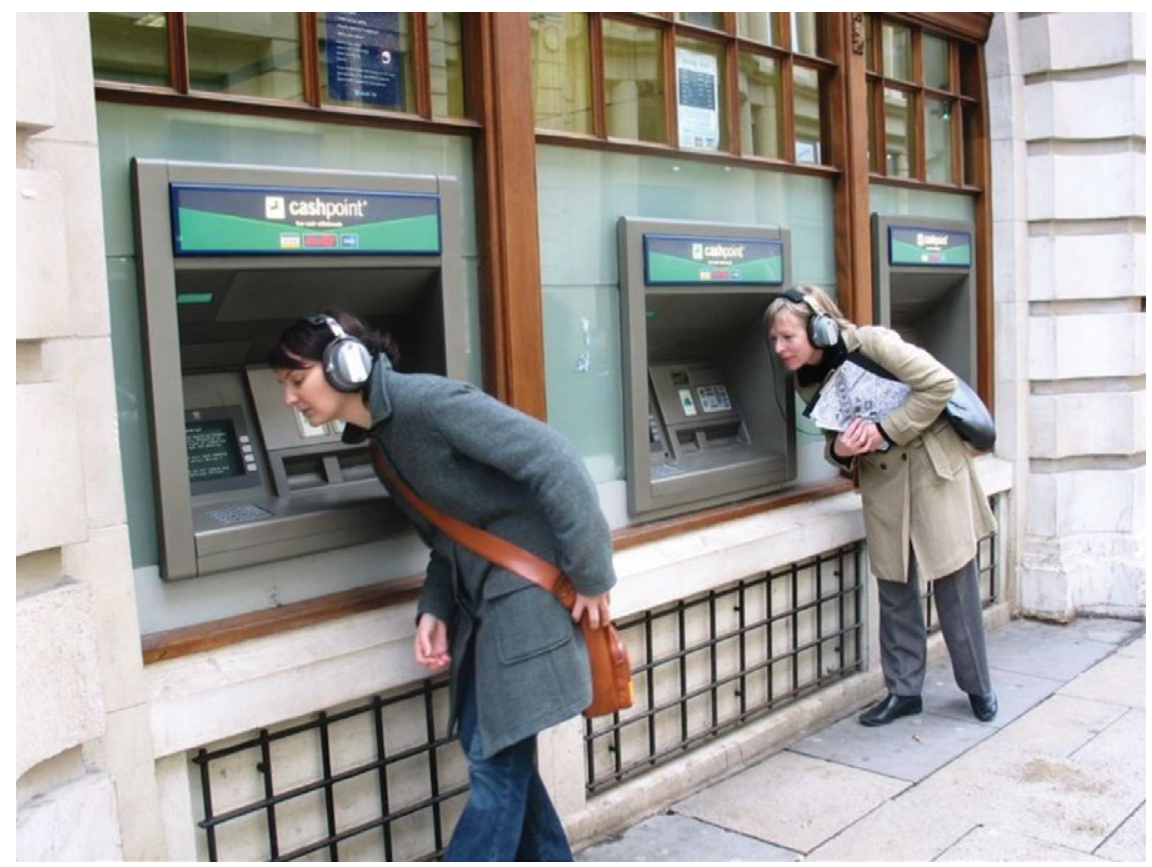

5. Christina Kubish, Electrical Walks Birmingham, 2006, Birmingham (C) Christina Kubish.

Pedro Ortuño Mengual y Gloria Lapeña Gallego, habían sido “elaborados en colaboración con antropólogos y escritores, con críticas mordaces sobre la problemática de conciliar la arqueología con el espacio urbano en México". ${ }^{73}$

Pero mientras Sophie Calle y Mariana Castillo Deball se apoyan en mecanismos textuales para ampliar la percepción, la intensidad estética de los paseos sonoros de Janet Cardiff reside en las interacciones entre visión y escucha, presente y pasado. La estructura de sus Audio walks y Video walks se desarrolla con la incorporación al momento presente de imágenes y sonidos que han sido previamente grabados. Algo en apariencia tan sencillo como grabar sonidos pertenecientes a un espacio determinado y trasladarlos a ese mismo lugar, pero

73. Pedro Ortuño Mengual y Gloria Lapeńa Gallego, "Reescribiendo la ciudad: contranarrativas urbanas en la obra de Martha Rosler, Janet Cardiff y Candy Chang", Arte, Individuo y Sociedad, 30, núm. I (24 de enero de 20I8): I20, http://dx.doi.org/I0.5209/ARIS.56459 (consultado el 17 de agosto de 2020). 
en otro momento, no lo es tanto. Este hecho establece un juego temporal entre pasado y presente, entre pasado y futuro, que se vincula directamente con la construcción del pensamiento simbólico, la metáfora y la evocación.

Se entregan a los asistentes un iPod y unos auriculares y se les pide que sigan el recorrido del video de ese lugar que ha sido previamente grabado y donde la voz de Cardiff va ofreciendo indicaciones orientativas. La superposición de realidades lleva a una extraña confusión perceptiva en el cerebro del espectador, pues los sonidos reales se mezclan con los grabados, y producen una vacilante incertidumbre entre presencia y ausencia, ficción y realidad. El investigador Xoán Xil López Rodríguez comenta al referirse a esta dicotomía:

Surge entonces la poderosa situación esquizofónica que antes mencionábamos en la que, no sólo escuchamos sonidos grabados en un lugar diferente — dislocadoscomo planteaba Schafer, sino que los escuchamos en el mismo lugar donde se registraron, pero en un momento diferente - desincronizados- Percibimos el sonido injertado, pero no vemos la fuente que lo produce y el espacio cobra un nuevo sentido en el vórtice en el que se encuentran nuestros pensamientos, las voces que cruzan nuestra cabeza, y la tensión entre lo presente y lo espectral. ${ }^{74}$

Janet Cardiff trabajó primero en solitario y posteriormente en colaboración con George Bures Miller, para desarrollar su proyecto artístico común bajo el nombre de Cardiff \& Miller. En sus propuestas indagan en el potencial del sonido como material para desarrollar un diálogo con el receptor, cuya concepción del entorno se ve alterada mientras camina. El canal de YouTube de los artistas recoge y explica el conjunto de sus Video walks (fig. 6)..$^{75}$

Finalizamos este apartado concluyendo que el paseo sonoro es un formato idóneo para comprender los vínculos existentes entre memoria, sonido y espacio. El paseo sonoro en el contexto del arte, no es sólo un hecho acústico, sino también un acontecimiento cultural, social y político, donde se crean espacios heterogéneos que se entrecruzan, dialogan y enriquecen mutuamente.

74. Xoán Xil López Rodríguez, "Señal/Ruido. Algunos usos del paisaje sonoro en el contexto del arte", tesis de doctorado (Vigo: Universidad de Vigo-Facultad de Bellas Artes-Departamento de Dibujo, 2015).

75. Gran parte de los trabajos y su descripción metodológica y conceptual pueden consultarse en el canal de YouTube de Cardiff \& Miller, https://www.youtube.com/channel/UC4uoVG5KTeWF5hnubp-lrA (consultado el I7 de agosto de 2020). 


\section{DOI: https://doi.org/10.22201/iie.18703062e.2021.119.2753}

\section{Proyecto Cartografías sonoras de Granada. Contexto teórico}

$\mathrm{Al}$ partir de estas consideraciones, emprendimos a principios de 2020 el proyecto Cartografías sonoras de Granada que, desde el interés por los elementos sensoriales que construyen el entramado urbano, se centra en el sonido para proponer una serie de paseos sonoros por la ciudad de Granada (España). Somos conscientes de que se trata de un análisis parcial dentro de la complejidad del estudio de la ciudad contemporánea, pero cada cultura, cada colectivo social, posee unas manifestaciones sonoras características que determinan su singularidad y, por este motivo, consideramos que el desarrollo de métodos en los que se contemplen las variables sonoras será de gran utilidad para fomentar una auténtica relación de intercambio entre el ser humano y el espacio que lo acoge, la ciudad.

El proyecto forma parte de una investigación más amplia sobre el caminar cuyo objetivo es revalorar la actividad de andar en la ciudad para aumentar el bienestar físico y psicológico de los habitantes, siguiendo la tendencia urbanística de las Cittá Slow ${ }^{76}$ movimiento nacido en Italia que promueve un habitar más humano en las ciudades, al fomentar el paseo y el ralentizar de los ritmos.

Nuestra investigación sobre el caminar como revaloración del cuerpo toma como punto de partida las teorías del antropólogo David Le Breton que afirma que el ser humano está hoy día relegado a una condición de humanidad sentada, ha perdido la relación con su ser corporal, se encuentra ajeno al espacio que le rodea y se está transformando en un autómata posthumano que ya no sabe apreciar la "saveur du monde" 77 (sabor del mundo). Ha perdido su capacidad sensorial y perceptiva unida a su condición corporal y es necesario restaurarla. Ésta es también, como hemos visto, la prerrogativa del urbanismo sensorial y de la arquitectura de enfoque fenomenológico como es la de Juhani Pallasmaa.

Los lugares que habitamos se han transformado en no lugares, según la expresión de Marc Augé, ${ }^{78}$ y hemos perdido la capacidad de asignar significados a los espacios que atravesamos, porque nuestros desplazamientos son cada vez más rápidos y virtuales, se tornan 'líquidos', como diría Zygmunt Bauman. ${ }^{79}$ No sentimos, no tocamos, no disfrutamos el espacio que habitamos,

76. https://www.cittaslow.es (consultado el I7 de agosto de 2020).

77. David Le Breton, L’Adieu au corps (París: Éditions Metailié, 2013), 229.

78. Marc Augé, Non-lieux. Introduction à une anthropologie de la surmodernité (París: Éditions du Seuil, 1992).

79. Zygmunt Bauman, Tiempos líquidos. Vivir en una época de incertidumbre, trad. Carmen Corral Santos (Ciudad de México: Tusquets Editores, 2008). 


\section{DOI: https://doi.org/10.22201/iie.18703062e.2021.119.2753}

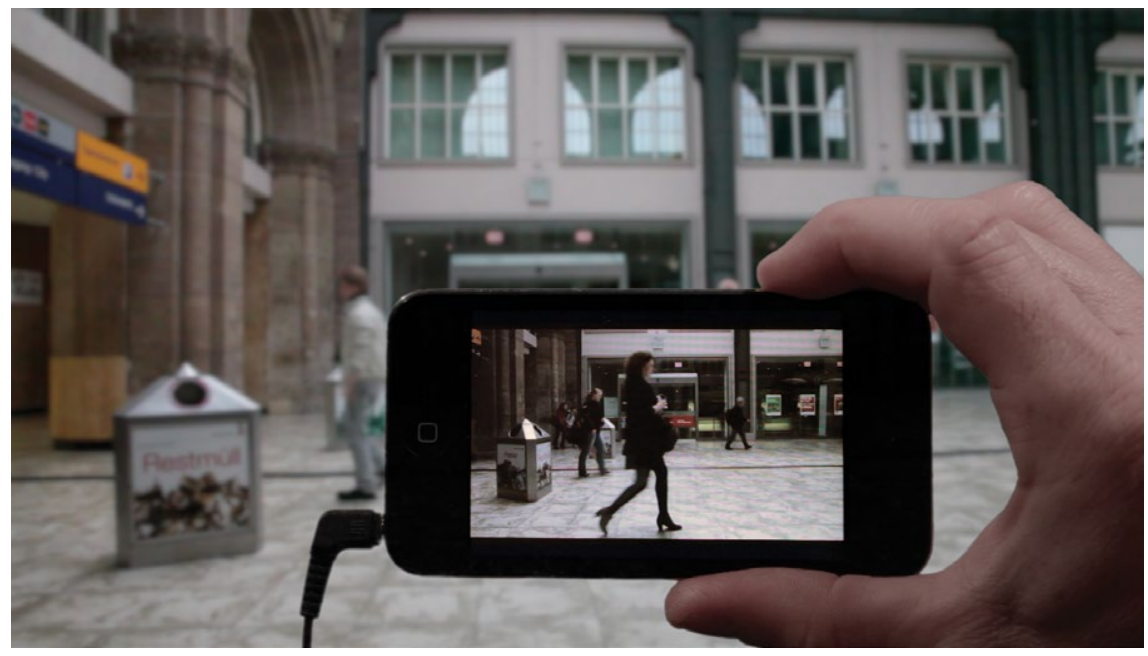

6. Janet Cardiff \& George Bures Miller, Alter Bahnhof Video Walk, 20I2, Video walk, 26', producido para la Documenta I3 de Kassel, Alemania. (C) Janet Cardiff \& George Bures Miller. Cortesía de los artistas y de Luhring Augustine, Nueva York.

vivimos en una continua abstracción virtual y, lo más grave, es que terminamos creyendo que es la realidad. La funcionalidad capitalista nos exige cada vez más rapidez y efectividad. Nuestra relación emocional y poética con el espacio está anestesiada. Estamos a las antípodas del famoso verso de Friedrich Hölderlin "Poéticamente habita el hombre...", título de una conferencia que Martin Heidegger impartió en $1955^{80}$ en la que reflexiona sobre el significado de vivir de forma poética para concluir que "poetizar" y "habitar" son en realidad lo mismo, "el poetizar constituye la esencia del habitar" ${ }^{81}$ Se hace cada vez más necesario, por tanto, recuperar la vivencia poética en las ciudades contemporáneas.

En el desarrollo del proyecto Cartografías sonoras de Granada, nuestro referente principal ha sido el libro Paisajes sonoros de Cuenca, ${ }^{82}$ que presenta la

80. Martin Heidegger, "Poéticamente habita el hombre...”, trad. Ruth Fischer de Walker, Revista de Filosofia 7, núms. I-2 ([195I] 20I7): 77-9I, https://revistafilosofia.uchile.cl/index.php/ RDF/article/view/4487I/4694I (consultado el I7 de agosto de 2020).

81. Citado por Javier Maderuelo, La idea de espacio en la arquitectura y el arte contemporáneos, 1960-1989 (Madrid: Ediciones Akal, 2008), I85.

82. Cristina Palmese, José Luis Carles Arribes y Antonio Jesús Alcázar, Paisajes sonoros de Cuenca (Ciudad Real: Ediciones de la Universidad de Castilla La Mancha, 20Io). 


\section{DOI: https://doi.org/10.22201/iie.18703062e.2021.119.2753}

sugestiva reconstrucción del paisaje sonoro de la ciudad de Cuenca (España). Entre los autores del libro, Cristina Palmese, arquitecta, creadora de Paisaje Sensorial Office-Lab ${ }^{83}$ y José Luis Carles, compositor y profesor de la Universidad Autónoma de Madrid, son artífices y coordinadores del programa de Radio Televisión Española, Radio Clásica, La casa del sonido ${ }^{84}$ dedicado a los paisajes sonoros cotidianos en un enfoque que denominan "ecología acústica". El libro Paisaje sonoro de Cuenca, acompañado de un $\mathrm{CD}$, contiene una minuciosa recopilación de los sonidos de esta ciudad, divididos en acústicos (sonidos puntuales generados por los seres vivos) y espaciales (sonidos del ambiente) que evidencian la importancia de la configuración geográfica en la creación de sonido. El interés de esta publicación, el cual compartimos y es el objetivo de nuestro proyecto Cartografías sonoras de Granada, es la revelación de una nueva concepción estética basada en la escucha como apreciación del paisaje desde una total inmersión en él. Al igual que los representantes del urbanismo sensorial o de la arquitectura de los sentidos, citados antes, los autores reivindican la importancia de la percepción in situ, del ver con los oídos o, como diría Pallasmaa, con Los ojos de la piel, ${ }^{85}$ en contraposición a la estética basada únicamente en lo visual que implica siempre una separación, una distancia entre el sujeto y el objeto. Los autores exponen el interesante concepto de ecología acústica y hacen notar que la escucha sonora revela una realidad a menudo en vías de extinción — sonidos naturales o de actividades humanas que pronto desaparecerán como las artesanales, los mercados, entre otros-, al evidenciar toda su riqueza y concientizándonos así de la necesidad de protegerla. La actitud de escucha es de por sí ecológica porque es una actitud de entrega, de contemplación, recogimiento y silencio, que conlleva la anulación del yo depredador.

\section{Descripción del proyecto}

Nuestro proyecto consiste en la elaboración de rutas sonoras en los diferentes barrios de Granada con el objetivo de revelar las experiencias sensoriales y

83. Cristina Palmese, "Paisaje Sensorial Office-Lab", 202I, https://paisajesensorial.com (consultado el I2 de febrero de 202I).

84. Cristina Palmese y José Luis Carles, La casa del sonido, 202I, https://www.rtve.es/alacarta/ audios/la-casa-del-sonido/ (consultado el I2 de febrero de 202I).

85. Pallasmaa, Los ojos de la piel, 2006. 
auditivas que brinda la ciudad. Al seguir las pautas del urbanismo sensual y de los autores arriba mencionados, queremos mostrar la riqueza emocional ofrecida por la escucha sonora y ofrecer una alternativa a la predominancia del sentido de la vista en la apreciación estética de la ciudad. Además, al ser rutas a pie, queremos evidenciar la riqueza perceptiva inherente a nuestra condición corporal que el caminar permite redescubrir plenamente. Fusionamos la actividad de la escucha con la de caminar, unión que hemos simbolizado con el logotipo del proyecto que representa un pie que es al mismo tiempo oreja (fig. 7).

El resultado del proyecto se recopila en una colección de libros electrónicos con textos, fotos, dibujos y sonidos. Cada libro está dedicado a un barrio diferente de Granada y muestra el interés específico de cada uno y descentraliza así el turismo que tiende a concentrarse exclusivamente en la Alhambra y el Albaycín, las dos zonas donde se aglomera el turismo masificado, consumista, movido por clichés histórico-monumentales que excluyen el interés por el lado más humano de la ciudad. La colección está compuesta en su inicio por seis ebooks — dedicados a los barrios Albayzín, Sacromonte, Alhambra, Centro, Chana, Zaidín-y está previsto, en un futuro, ampliar la colección a los 36 barrios de la ciudad.

Presentamos en el mapa de la ciudad de Granada las zonas elegidas como objeto de elaboración de los primeros seis ebooks (fig. 8). Todos los libros contienen un breve texto de presentación del barrio, su historia y su realidad actual. En el interior se encuentran también, de manera aleatoria, algunas poesías, versos sueltos o pasajes literarios de escritores actuales o pasados, relacionados con el paisaje urbano en cuestión, vista la importante relación entre narrativa y sonido como ya hemos mencionado en la primera parte del artículo.

Los sonidos se han organizados en siete grupos — sonidos humanos, animales, naturales, objetuales, mecánicos, rituales y musicales-, cada uno con un color específico correspondiente al color de la ruta a pie para escucharlo. Cada grupo de sonidos contiene, a su vez, varios tipos de sonidos representados por distintos iconos. Por ejemplo: los sonidos humanos incluyen las voces de diferentes edades, los distintos idiomas, las risas, los gritos, los murmullos, etc. Los sonidos naturales presentan iconos de agua, río, fuente, lluvia, viento, hojas secas, etc. El número de posibles iconos es ilimitado, así como son infinitos los sonidos potenciales. Una vez más, es una invitación a la escucha de la diversidad (fig. 9).

Cada libro presenta al principio un mapa de las rutas sonoras, formado por las líneas de los distintos colores de cada grupo de sonido, similar a un plano 


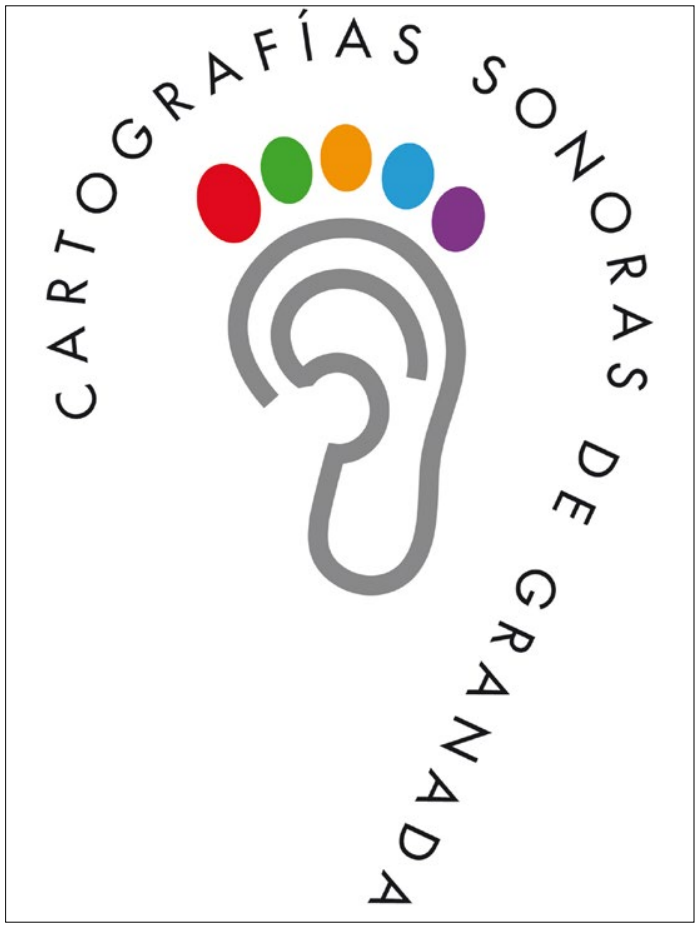

7. Laura Apolonio y Mar GarridoRomán, logotipo de las Cartografias Sonoras de Granada, 2020, Granada, España. (C) Laura Apolonio y Mar Garrido-Román.

del metro, donde las estaciones son puntos de escucha, caracterizados por los iconos de los sonidos.

Aunque toda la colección presenta un estilo gráfico unitario, cada uno de los libros introduce un elemento gráfico diferente marcado por la peculiaridad del barrio, con fotos o ilustraciones distintas, así como otras recopilaciones de sonidos. En cada página, al presionar sobre el punto adyacente al icono se activará el sonido correspondiente (fig. Io).

El proyecto incluye también la posibilidad de desarrollar una app para el Patronato de Turismo de Granada, que estará disponible para descargar de forma totalmente gratuita y presentará las diferentes rutas en los distintos barrios. También permitirá a los usuarios grabar sonidos y compartirlos con una comunidad de usuarios de tal forma que la biblioteca de sonidos irá ampliándose con el tiempo y con la participación de los ciudadanos, se espera, así, generar una concientización cada vez mayor sobre la riqueza del paisaje sonoro de cada barrio de la ciudad. 


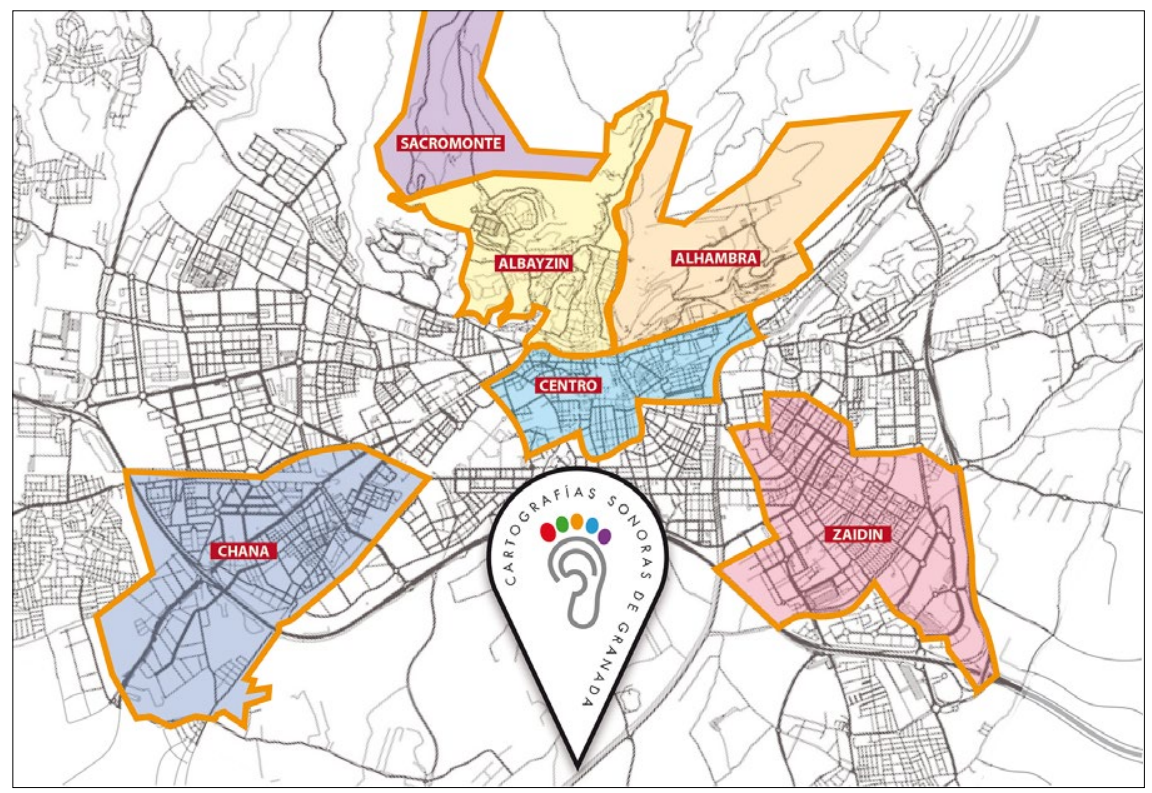

8. Laura Apolonio y Mar Garrido-Román, Mapa general con localización de los barrios elegidos, 2020, Granada, España. (C) Laura Apolonio y Mar Garrido-Román.

Aunque el proyecto esté todavía en construcción es posible observar su genealogía y desarrollo, así como escuchar una muestra de los sonidos cartografiados en el siguiente enlace: www.lauraapolonio.com/rutas-sonoras.

\section{Conclusiones}

Desde las pautas del urbanismo sensorial al proyecto Cartografias sonoras de Granada pasando por la historia del soundwalking y mostrando el potencial creativo del arte sonoro, hemos recalcado la importancia de recuperar el lado sensorial, lúdico, poético de nuestra relación con el entorno y con la ciudad que habitamos, para tomar así conciencia de la riqueza que alberga la vida humana en sus relaciones, deseos, emociones y creatividad, saliendo de la lógica funcionalista, ceñida al cumplimiento de objetivos de producción, acumulación y beneficio.

Por desgracia, este enfoque urbanístico que evidencia la importancia del ambiente sonoro en nuestra percepción del espacio y en la construcción de 
DOI: https://doi.org/10.22201/iie.18703062e.2021.119.2753

46

LAURA APOLONIO Y MAR GARRIDO-ROMÁN

SONIDOS HUMANOS
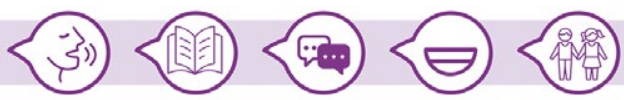

Voces, historias. murmullos, risas, niños.

SONIDOS MUSICALES
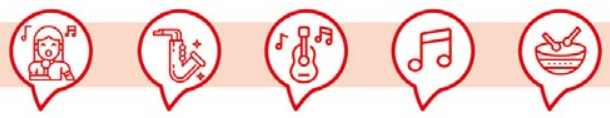

Músicos callejeros. Sonidos musicales. Instrumentos...

SONIDOS RITUALES
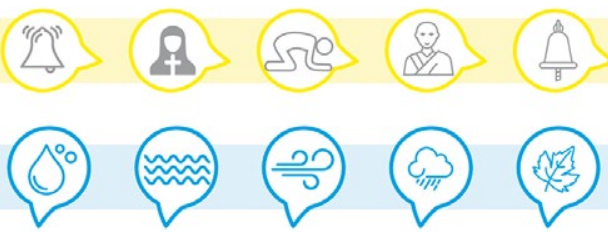

Campanas, Cantos religiosos, Oraciones. Danzas rituales...

SONIDOS NATURALES
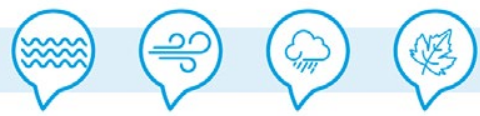
Agua, Rio, Viento
Hojas secas, Uluvia,
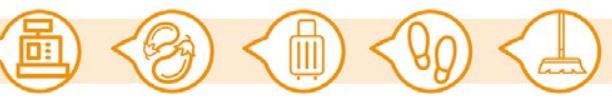

Cualquier objeto que produzca un sonido SONIDOS OBJETUALES
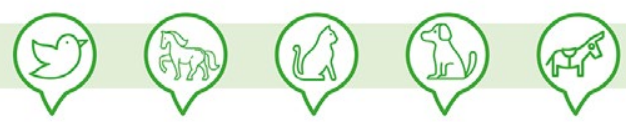

Pójaros, Gatos, Perros, Caballos, Burros,

SONIDOS MECÁNICOS
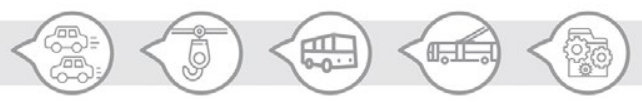

Coches, Grúas, Tranvias, Autobuses.

9. Laura Apolonio y Mar Garrido-Román, Organización de los grupos de sonidos y ejemplos de iconos, 2020, Granada, España. (C) Laura Apolonio y Mar Garrido-Román.

nuestra identidad se contrapone, al día de hoy, a la degradación ocasionada por la arquitectura contemporánea — con calles demasiado anchas que imposibilitan la intimidad de la escucha- y por la contaminación acústica debida a la sobrepoblación y sobreaceleración de la vida. En las condiciones de vida moderna el ambiente sonoro pasa casi siempre desapercibido. Como escribe Pallasmaa: "Nuestros oídos han sido cegados." 86

Urge la necesidad de un urbanismo que favorezca el despertar de la percepción de lo cotidiano, descubrir su riqueza, invitar a ralentizar, pasear, sentir con el cuerpo la infinita riqueza del ambiente sonoro que nos envuelve y escuchar la vida en sus efímeras expresiones. La escucha es una actitud que adopta una perspectiva de sostenibilidad porque invita a volver a la sencillez, a nuestro cuerpo, a eliminar lo superfluo y a prestar atención a nuestro entorno percatándonos de su riqueza y sobre todo de su diversidad. Cuando escuchamos

86. Juhani Pallasmaa, Los ojos de la piel, 52 . 

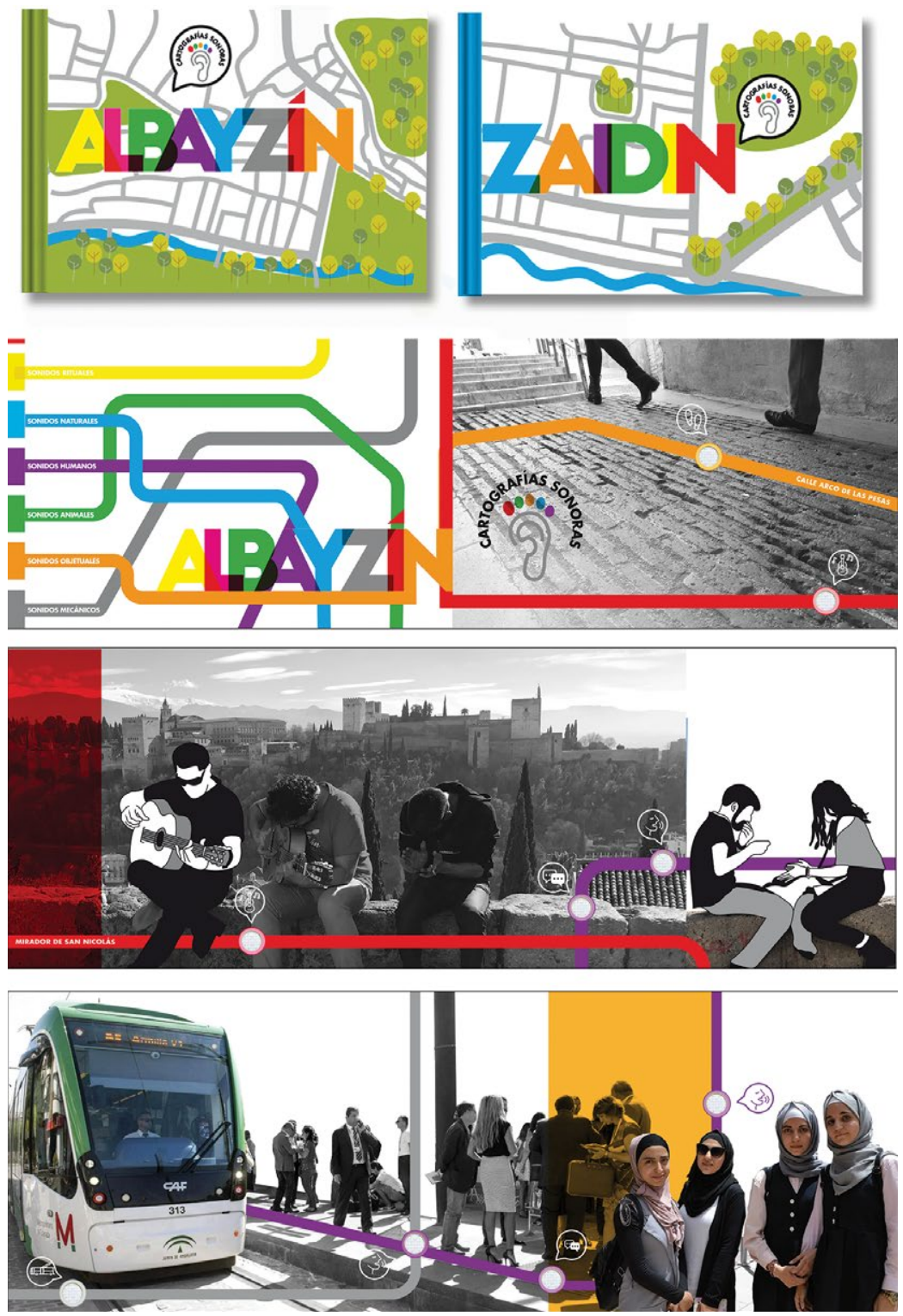

Io. Laura Apolonio y Mar Garrido-Román, Albayzin y Zaidin. Cartografías sonoras de Granada, portadas y páginas interiores, libro electrónico (Granada, España, 2020). (C) Laura Apolonio y Mar Garrido-Román. 


\section{DOI: https://doi.org/10.22201/iie.18703062e.2021.119.2753}

atentamente, vivimos el presente, habitamos el instante y nos dejamos sorprender por la multitud de sonidos que percibimos a los que por lo cómún no prestamos atención. Conectamos con nuestro lado más poético y abandonamos lo funcional. Descubrimos lo que Perec llama lo "infraordinario", ${ }^{87}$ es decir, el milagro dentro de lo banal, lo extraordinario en lo cotidiano. Entonces nos invade el sentimiento estético más profundo, lo que para David Le Breton es el efecto de cualquier paseo, "l'émerveillement du monde" 88 (el asombro maravillado del mundo).

En las fechas en las que escribimos este artículo, no podemos dejar de mencionar la crisis sanitaria COVID-I9 que nos acecha, que ha convulsionado todo el conjunto de las relaciones sociales, las instituciones y los valores. Esta conmoción de la realidad, ha transformado el material auditivo recopilado hace tan sólo unos meses en un documento ya histórico. Ahora las aglomeraciones turísticas y las multitudes urbanas han desaparecido. Aunque ya se habla de un "romanticismo del coronavirus" que propone este momento como la oportunidad para detenernos, para observar, para escuchar y en definitiva promover el sosiego y la desaceleración, tampoco podemos engañarnos: basta salir a las calles para observar que la calma es tensa y la inactividad ha sido impuesta, no decidida. Aun así, numerosos ciudadanos han podido disponer de una temporalidad más lenta, un aire menos contaminado y nuevos sonidos naturales (pájaros, ríos...) han vuelto a surgir en el paisaje urbano.

Pasado el estado de alarma, en la nueva fase de "anormal normalidad", todos los países del planeta siguen enfrentando la acometida de esta pandemia. Parece claro que éste pueda ser el momento de rotunda transformación. ¿Qué huellas sonoras dejará la distancia social en las ciudades? ¿Qué futuro sonoro y urbano nos espera? Aunque, por un lado, nos asusta la incertidumbre sanitaria y económica, por otro, se vislumbra una tenue esperanza de que pueda nacer un significativo cambio de paradigma. Como ya se ha citado tantas veces, la palabra china para crisis 危機 se compone de dos caracteres: riesgo y oportunidad. Confiemos pues en que la segunda se abra camino.

87. Georges Perec, L’infra-ordinaire (París: Éditions du Seuil, 1989). Kindle.

88. David Le Breton, "Pourquoi prendre le temps de marcher" (¿Por qué tomarse el tiempo de caminar?), I7 de julio, 2020, https://www.rfi.fr/fr/podcasts/20200715-pourquoi-prendre-letemps-marcher (consultado el 20 de agosto de 2020). 